\title{
Application of Oil-in-Water Nanoemulsion Carrying Size-Defined Gold Nanoparticles Synthesized by Non-thermal Plasma for the Human Breast Cancer Cell Lines Migration and Apoptosis
}

\author{
Anna Dzimitrowicz ${ }^{1} \cdot$ Aleksandra Bielawska-Pohl $^{2} \cdot$ Pawel Pohl $^{1}$. \\ Dorota Jermakowicz-Bartkowiak ${ }^{3} \cdot$ Piotr Jamroz $^{1} \cdot$ Magdalena Malik-Gajewska $^{4}$. \\ Aleksandra Klimczak ${ }^{2} \cdot$ Piotr Cyganowski ${ }^{3}$
}

Received: 18 October 2019 / Accepted: 7 March 2020 / Published online: 17 March 2020

(c) The Author(s) 2020

\begin{abstract}
In this work, the gold nanoparticles (AuNPs) were synthesized using pulse-modulated radio-frequency atmospheric pressure glow discharge (pm-rf-APGD). By tailoring selected operating parameters of the pm-rf-APGD reaction-discharge system, the experimental conditions for the synthesis of raw-AuNPs with controlled optical and structural properties were found. The colloidal suspension of the size-controlled raw-AuNPs was mixed with an aqueous solution of gelatine and turmeric oil to produce an oil-in-water $(\mathrm{O} / \mathrm{W})$ nanoemulsion. AuNPs loaded into the nanoemulsion were characterized using ultraviolet-visible absorption spectrophotometry, dynamic light scattering, scanning electron microscopy supported by energy dispersive X-ray spectroscopy, and transmission electron microscopy equipped with selected area X-ray diffraction. Additionally, attenuated total reflectance Fourier-transform infrared spectroscopy was used to confirm the efficient functionalization of the AuNPs by nanoemulsion component. It was revealed that AuNPs were mostly spherical with an average size of $4.6 \pm 1.0 \mathrm{~nm}$ and a face-centered cubic crystal system. The developed O/W nanoemulsion carrying AuNPs was applied towards the human breast cancer cell lines MCF7 and MDA-MB-231. It was found that it exhibited the cytotoxicity towards the breast cancer cells while were non-cytotoxic towards the non-tumour breast cells MCF10A. Moreover, it also inhibited the migration of the invasive cancer breast cells (line MDA-MB-231) and hence, could prevent the breast cancer metastasis.
\end{abstract}

Keywords Cold atmospheric pressure plasma $\cdot$ Pulse-modulated radio-frequency atmospheric pressure glow discharge $\cdot$ Nanomaterials $\cdot$ Cytotoxicity

\section{Abbreviations \\ ATR FT-IR Attenuated total reflectance Fourier-transform infrared spectroscopy \\ AuNPs Gold nanoparticles \\ CAPP Cold atmospheric pressure plasma}

Anna Dzimitrowicz

anna.dzimitrowicz@pwr.edu.pl

Extended author information available on the last page of the article 


$\begin{array}{ll}\text { DAMP } & \text { 4,6-Diamino-2-mercaptopyrymidyne } \\ \text { dc-APGD } & \text { Direct current atmospheric pressure glow discharge } \\ \text { D }_{\mathrm{H}} & \text { Hydrodynamic diameter } \\ \text { DF } & \text { Degrees of freedom } \\ \text { DLS } & \text { Dynamic light scattering } \\ \text { DOE } & \text { Design of experiments } \\ \text { EDX } & \text { Energy dispersive X-ray spectroscopy } \\ \text { fcc } & \text { Face-centered cubic } \\ \text { FAAS } & \text { Flame atomic absorption spectrometry } \\ \text { FLA } & \text { Flowing liquid anode } \\ \text { FLC } & \text { Flowing liquid cathode } \\ \text { FLE } & \text { Flowing liquid electrode } \\ \text { GSH } & \text { Glutathione } \\ \text { LSPR } & \text { Localized surface plasmon resonance } \\ \text { MCF7 } & \text { Human breast cancer cell lines } \\ \text { MCF10A } & \text { Non-tumour breast cells } \\ \text { MDA-MB-231 } & \text { Human breast cancer cell lines } \\ \text { MS } & \text { Mean of squares } \\ \text { O/W } & \text { Oil-in-water } \\ \text { pm-rf-APGD } & \text { Pulse-modulated radio-frequency atmospheric pressure glow discharge } \\ \text { PSMA-1 } & \text { Prostate-specific membrane antigen } \\ \text { PVA } & \text { Polyvinyl alcohol } \\ \text { PVP } & \text { Polyvinylpyrrolidone } \\ \text { RONS } & \text { Reactive oxygen and nitrogen species } \\ \text { RSM } & \text { Response surface methodology } \\ \text { SAED } & \text { Selected area electron diffraction } \\ \text { SEM } & \text { Scanning electron microscopy } \\ \text { SS } & \text { Sum of squares } \\ \text { TEM } & \text { Transmission electron microscopy } \\ \text { UV-Vis } & \text { Ultraviolet-visible } \\ & \end{array}$

\section{Introduction}

Currently, a rapid development in the production and utilization of nanomaterials of certain properties has been observed. Among many nanomaterials designed for defined purposes, a special attention has been paid to the synthetic organic and inorganic nanoparticles (NPs) that are designed for the medical applications and can be produced in the laboratory settings. The organic NPs might be loaded into the polymeric micelles and liposomes, improving the therapeutic efficacy of the anticancer drugs [1]. Particularly, the polymeric micelles with the amphiphilic molecules are used in the delivery of the water-insoluble drugs [2]. The liposomes are of interest as well as they are highly biocompatible and biodegradable [3]. These novel selective drug-delivery systems are an important approach that has a great potential to overcome the problems associated with the systemic toxicity and poor bioavailability of the antineoplastic drugs [4].

Although the mentioned organic nanostructures draw a high attention, the inorganic gold nanoparticles (AuNPs) are involved in one of the most studied cancer treatment approaches [5]. Indeed, the AuNPs can provide many favourable properties to a drug, especially 
including a longer elimination time, an increased drug-site contact time, and a reduced drug resistance $[6,7]$. There are many methods used to produce the AuNPs in the laboratory settings, counting the chemical reduction [8], the sol-gel precipitation [9], and the green synthesis [10]. Unfortunately, all these methods usually involve the multi-step processes and complex chemical treatments that require a relatively high labour investment and generate costs. Moreover, the efficiency of the synthesis of the AuNPs with the above-mentioned methods can be limited, while the fabricated nanomaterials are still not ready-to-use and commonly need an additional purification before their specific biological or medical applications [10, $11]$.

A solution to the obvious disadvantages of the methods of the AuNPs synthesis cited above is the method based on cold atmospheric pressure plasma (CAPP), which has been proven to efficiently and simply fabricate them in a fast, single-step process [12-30]. In this novel method, the AuNPs' precursor solutions are treated by the different CAPP sources, resulting in the formation of the Au nanostructures of the certain morphology, which can additionally be tuneable by the appropriate changes in the operating parameters of these sources. Here, the AuNPs synthesis is associated with the action of the reactive oxygen and nitrogen species (RONS) as well as the hydrogen radicals $(\mathrm{H} \cdot)$ and the hydrated electrons $\left(\mathrm{e}_{\mathrm{aq}}^{-}\right)$that are efficiently generated in the CAPP phase, the treated solutions, and the interfacial zone [12]. The method provides the AuNPs that have the desirable and reproducible physical dimensions, crystallinity, and spectral properties, and are ready-to-use without any initial pre-treatments. Nevertheless, all the previously reported CAPP sources were operated in non-flowing reaction-discharge systems [12-30], considerably limiting in this way the scale of the AuNPs production.

Bearing this in mind, our research group has developed and extensively examined the CAPP-based method for the noble metal nanostructures synthesis in the high-throughput, continuous-flow reaction-discharge systems [31-34]. In these systems, direct current atmospheric pressure glow discharge (dc-APGD) was operated between the surface of a flowing liquid anode (FLA) [32, 33] or a flowing liquid cathode (FLC) [31-34] and a nozzle $\operatorname{Ar}$ jet $[31,32,34]$ or a sharpened pin-type electrode (with no discharge gas required, completely in the open-to-air atmosphere) [33]. By appropriately adjusting the working parameters of the dc-APGD systems, including the discharge current [31,33], the AuNPs precursor solution flow rate [40,42], and the flow rate of the jet-supporting gas [31], it was possible to find the operating parameters under which the size-defined AuNPs were reproducibly produced. In addition, the obtained AuNPs were stabilized by the addition of a natural biopolymer, i.e., gelatin [31, 32, 34], or a synthetic polymer, i.e., polyvinylpyrrolidone (PVP) [34] or polyvinyl alcohol (PVA) [34], to the precursor solutions or just by the electrostatical repulsions of the AuNPs [33]. To the best of our knowledge, this is a first work in which size-controlled raw-AuNPs have been synthesized with the aid of the pulse-modulated radio-frequency atmospheric pressure glow discharge (pm-rf-APGD) in the employed for that purpose highly-throughput reaction-discharge system under defined operating conditions. Because the polarity of the electrodes changes continuously, the obtained nanostructures might be monodisperse with the low size distribution.

According to the World Cancer Research Fund International, the breast cancer is the most prevalent cancer among women with approximately 2 million new cases reported in 2018 [35]. The high number of the breast cancer patients has led to a significant interest in the development of the novel, efficient, and faster therapies against it [5]. These therapies are supported by the recent progress in molecular biology [36, 37] and in pharmacology [38], as highlighted by many patents and research papers in the last 15 years [39-41]. Besides the application of the new therapies, decreasing the incidence of the breast cancer 
and the number of the related deaths [5], there are many additional issues that must be overcome. It includes the improvement of the quality of live of the breast cancer patients by minimizing the side effects of the applied therapies [5, 42]. A special attention has lately been paid to nanotechnology, which seems nowadays to be one of the most promising research fields that may help to overcome the drawbacks related to the side effects of the convention cancer therapies and improve the quality of live as well [5]. The nanotechnology-based therapies are associated with the interaction of the cellular and molecular components with the nanomaterials that possess the certain properties [43].

To enhance the efficiency of the AuNPs in the cancer treatment and detection, several ligands, including lycopene [44], folate-decorated polymers [45], prostate-specific membrane antigen (PSMA-1) [46], as well as 4,6-diamino-2-mercaptopyrimidine (DAMP) and glutathione (GSH) [47], have successfully been attached to the surface of these nanostructures. However, Curcuma longa (turmeric or "Indian saffron"), a popular herbal raw material [48], is particularly interesting for that purpose. The turmeric rhizomes are widely applied in contemporary medicine because they contain the biologically active compounds such as p-cymene, 1,8-cineole, terpinolene, ar-turmeone, curlone, cucruphenol, turmerone, $\beta$-bisabolene, p-cymen-8-ol, and $\alpha$-pinen [48]. Toden et al. [49] lately showed that the antiinflammatory efficiency of turmeric towards the colitis could be improved by applying its essential oil [49]. Zhou et al. [50] and Mirzaei et al. [51] summarized that turmeric could affect the cellular and molecular pathways entangled in the cancer development.

Due to the biological activity of turmeric [48-51], it was decided in the present work to use turmeric essential oil (i) to functionalize the surface of the raw-AuNPs produced with pm-rf-APGD under defined operating conditions to enhance their cytotoxicity towards the human cancer cell lines and (ii) to prepare the homogenous oil-in-water $(\mathrm{O} / \mathrm{W})$ nanoemulsion carrying the produced raw-AuNPs. In the later case, it was motivated by the fact that the nanoemulsions are the most promising nanocarries used to improve the therapeutic efficacy of the anticancer drugs, commonly overcoming the problems associated with their systemic toxicity and poor bioavailability $[52,53]$. According to the best of our knowledge, this is a first work in which size-defined raw-AuNPs have been immediately mixed with the gelatine and turmeric oil, resulting in the O/W nanoemulsion production. For that reason, the main aim of this studies was to synthesize the AuNPs with the aid of the pm-rf-APGD reaction-discharge system, working in the highly-throughput mode. The effect of the operating parameters of the pm-rf-APGD reaction-discharge system on the wavelength of the maximum $\left(\lambda_{\max }\right)$ of the localized surface plasmon resonance (LSPR) absorption band of the synthesized raw-AuNPs, as determined by ultraviolet-visible (UV-Vis) absorption spectrophotometry (UV-Vis), and their mean hydrodynamic diameter $\left(\mathrm{D}_{\mathrm{H}}\right)$, as determined by dynamic light scattering (DLS), was studied using the design of experiments (DOE) followed by the response surface methodology (RSM). The both responses of the examined system were next modeled in reference to the size-controlled production of the uncoated spherical Au nanostructures. The resultant colloidal suspensions of the AuNPs of a certain size were mixed with an aqueous solution of gelatine, being a natural biopolymer and emulsifier, and turmeric oil to obtain the $\mathrm{O} / \mathrm{W}$ nanoemulsion carrying the AuNPs functionalized by nanoemulsion components (turmeric oil and aqueous solution of gelatine). The utilization of gelatine was related to the stabilization and protection from aggregation AuNPs produced with the aid of the pm-rf-APGD. The AuNPs loaded into the nanoemulsion were characterized to reveal their optical and structural properties as well as to confirm their functionalization. Finally, the developed O/W nanoemulsion carrying AuNPs was examined with respect to its migration and cytotoxic activity against the cancer cells, 
i.e., the human breast cancer cell lines MCF7 and MDA-MB-231, as well as a non-tumour breast cells (line MCF10A).

\section{Experimental Procedures}

\section{Reagents and Solutions for the Raw-AuNPs Synthesis}

Solid chloroauric acid tetrahydrate $\left(\mathrm{HAuCl}_{4} \times 4 \mathrm{H}_{2} \mathrm{O}\right.$, Pol-Aura, Olsztyn, Poland $)$ was used as the precursor for the synthesis of the uncoated Au nanostructures. To prepare the working solutions of the $\mathrm{Au}(\mathrm{III})$ at concentrations of 50,125 and $200 \mu \mathrm{g} \mathrm{mL}^{-1}$, the appropriate amounts of $\mathrm{HAuCl}_{4} \times 4 \mathrm{H}_{2} \mathrm{O}$ were dissolved in deionized water in the volumetric flasks and diluted using deionized water to the required volume.

\section{Optimization of the Raw-AuNPs Synthesis by the Response Surface Methodology}

Generally, to produce the raw-AuNPs by the CAPP-based synthesis method, the pm-rfAPGD based reaction-discharge system was used (Fig. 1) that was previously reported for the continuous-flow synthesis of the pectin-stabilized Ag nanostructures [54]. Here, a new set of the operating parameters that allows to obtain the entirely raw-AuNPs of the defined granulometric properties were selected and validated. Overall, in the high-throughput pmrf-APGD-based reaction-discharge system, a AuNPs precursor solution (3), being the FLE of the discharge system, was pumped to a quartz chamber by a four channel peristaltic pump (Masterflex L/S, Cole-Parmer ${ }^{\circledR}$, Vernon Hill, Il, USA) via a quartz-graphite tube (3, 7). At the interface between the surface of the FLE solution (3) and the pin-type tungsten electrode of the OD $=4.0 \mathrm{~mm}(1)$, pm-rf-APGD (6) was sustained and stably operated. Operating pm-rf-APGD under the defined experimental conditions (see below in Table 1), the treated solution was collected for the further experiments.
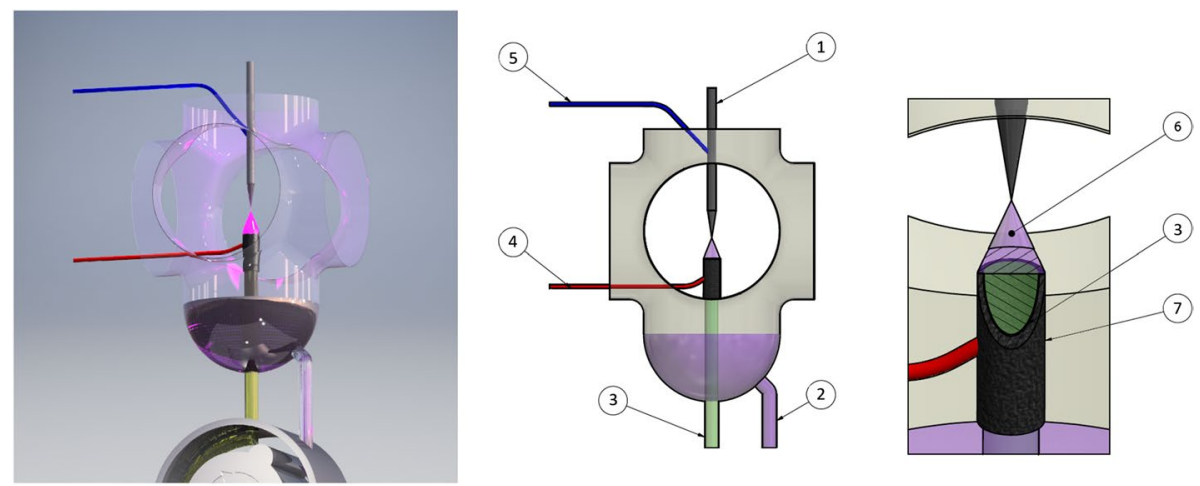

Fig. 1 The pm-rf-APGD-based reaction-discharge system used for the high-throughput continuous-flow production of the uncoated Au nanostructures. The description of the items in the scheme: (1) the pin-type tungsten electrode, (2) the product: the raw-AuNPs, (3) a AuNPs precursor solution (acting as the FLE), delivered to a quartz discharge chamber, $(4,5)$ the plugins of the pm-rf voltage, (6) pm-rf-APGD, (7) the quartz-graphite tube 
Table 1 The Box-Behnken response surface design matrix with the actual and coded values of the studied operating parameters of the reaction-discharge system, the randomized run order, and the response of the system, i.e., the $\lambda_{\max }$ (in $\mathrm{nm}$ ) of the LSPR absorption band of the resultant raw-AuNPs, and their $\mathrm{D}_{\mathrm{H}}$ (in $\mathrm{nm}$ )

\begin{tabular}{|c|c|c|c|c|c|c|}
\hline \multirow[t]{2}{*}{ Run order } & \multicolumn{4}{|c|}{ Actual (and coded) levels of the operating parameters } & \multicolumn{2}{|l|}{ Response } \\
\hline & $\mathrm{A}\left(\mathrm{mL} \min ^{-1}\right)$ & $\mathrm{B}(\mathrm{kHz})$ & $\mathrm{C}(\%)$ & $\mathrm{D}\left(\mu \mathrm{g} \mathrm{mL}^{-1}\right)$ & $\lambda_{\max }^{\mathrm{a}}(\mathrm{nm})$ & $\mathrm{D}_{\mathrm{H}}^{\mathrm{b}}(\mathrm{nm})$ \\
\hline 1 & $5.0(0)$ & $0.7(-1)$ & $50(0)$ & $200(+1)$ & 544 & $2.1 \pm 0.9$ \\
\hline 2 & $6.0(+1)$ & $1.5(0)$ & $50(0)$ & $50(-1)$ & 540 & $0.9 \pm 0.5$ \\
\hline 3 & $6.0(+1)$ & $1.5(0)$ & $50(0)$ & $200(+1)$ & 549 & $3.4 \pm 0.8$ \\
\hline 4 & $5.0(0)$ & $0.7(-1)$ & $50(0)$ & $50(-1)$ & 536 & $1.6 \pm 0.6$ \\
\hline 5 & $4.0(-1)$ & $1.5(0)$ & $50(0)$ & $200(+1)$ & 545 & $1.8 \pm 0.7$ \\
\hline 6 & $5.0(0)$ & $1.5(0)$ & $70(+1)$ & $50(-1)$ & 540 & $1.9 \pm 0.7$ \\
\hline 7 & $5.0(0)$ & $0.7(-1)$ & $70(+1)$ & $125(0)$ & 542 & $1.5 \pm 0.9$ \\
\hline 8 & $6.0(+1)$ & $1.5(0)$ & $70(+1)$ & $125(0)$ & 540 & $1.2 \pm 0.5$ \\
\hline 9 & $4.0(-1)$ & $1.5(0)$ & $50(0)$ & $50(-1)$ & 537 & $3.1 \pm 0.7$ \\
\hline $10^{\mathrm{c}}$ & $5.0(0)$ & $1.5(0)$ & $50(0)$ & $125(0)$ & 543 & $3.3 \pm 0.6$ \\
\hline 11 & $5.0(0)$ & $1.5(0)$ & $30(-1)$ & $200(+1)$ & 546 & $2.7 \pm 1.2$ \\
\hline 12 & $4.0(-1)$ & $1.5(0)$ & $70(+1)$ & $125(0)$ & 538 & $1.3 \pm 0.6$ \\
\hline 13 & $5.0(0)$ & $2.3(+1)$ & $50(0)$ & $200(+1)$ & 543 & $0.9 \pm 0.3$ \\
\hline 14 & $5.0(0)$ & $1.5(0)$ & $70(+1)$ & $200(+1)$ & 541 & $0.9 \pm 0.4$ \\
\hline 15 & $5.0(0)$ & $1.5(0)$ & $30(-1)$ & $50(-1)$ & 534 & $1.5 \pm 0.5$ \\
\hline 16 & $5.0(0)$ & $0.7(-1)$ & $30(-1)$ & $125(0)$ & 540 & $1.3 \pm 0.6$ \\
\hline 17 & $5.0(0)$ & $2.3(+1)$ & $50(0)$ & $50(-1)$ & 533 & $1.1 \pm 0.4$ \\
\hline 18 & $5.0(0)$ & $2.3(+1)$ & $30(-1)$ & $125(0)$ & 541 & $0.9 \pm 0.4$ \\
\hline 19 & $4.0(-1)$ & $2.3(+1)$ & $50(0)$ & $125(0)$ & 537 & $1.9 \pm 0.6$ \\
\hline 20 & $6.0(+1)$ & $2.3(+1)$ & $50(0)$ & $125(0)$ & 538 & $2.7 \pm 0.5$ \\
\hline 21 & $4.0(-1)$ & $0.7(-1)$ & $50(0)$ & $125(0)$ & 539 & $3.0 \pm 0.6$ \\
\hline $22^{\mathrm{c}}$ & $5.0(0)$ & $1.5(0)$ & $50(0)$ & $125(0)$ & 538 & $3.8 \pm 0.8$ \\
\hline $23^{c}$ & $5.0(0)$ & $1.5(0)$ & $50(0)$ & $125(0)$ & 540 & $3.2 \pm 0.8$ \\
\hline 24 & $6.0(+1)$ & $1.5(0)$ & $30(-1)$ & $125(0)$ & 542 & $1.3 \pm 0.5$ \\
\hline 25 & $6.0(+1)$ & $0.7(-1)$ & $50(0)$ & $125(0)$ & 539 & $1.2 \pm 0.8$ \\
\hline 26 & $4.0(-1)$ & $1.5(0)$ & $30(-1)$ & $125(0)$ & 540 & $1.9 \pm 0.8$ \\
\hline 27 & $5.0(0)$ & $2.3(+1)$ & $70(+1)$ & $125(0)$ & 538 & $2.3 \pm 0.8$ \\
\hline
\end{tabular}

${ }^{\text {a }}$ The wavelength of the maximum $\left(\lambda_{\max }\right)$ of the localized surface plasmon resonance (LSPR) absorption band of the raw-AuNPs as determined by UV-Vis

${ }^{b}$ The average size corresponding to the hydrodynamic diameter $\left(D_{H}\right)$ as determined by DLS

${ }^{\mathrm{c}}$ The center point - the operating parameters $\mathrm{A}, \mathrm{B}, \mathrm{C}$, and $\mathrm{D}$ were set at $(0,0,0,0)$. A-The flow rate of the FLE solution (in $\mathrm{mL} \mathrm{min}^{-1}$ ). B-The frequency of the pulse modulation of the rf current (in $\mathrm{kHz}$ ). $\mathrm{C}-$ The duty cycle (in \%). D-The AuNPs precursor concentration (in $\mu \mathrm{g} \mathrm{mL} \mathrm{m}^{-1}$ )

To tune the size of the raw-AuNPs synthesized in the applied pm-rf-APGD-based reaction-discharge system (Fig. 1), the effect of the selected operating parameters of this system was studied and modeled with the aid of the Box-Behnken DOE followed by the RSM [31, 33]. The following operating parameters were considered: (1) the flow rate of the FLE solution (A, in $\left.\mathrm{mL} \mathrm{min}^{-1}\right)$; (2) the frequency of the pulse modulation of the $\mathrm{rf}$ current (B, in $\mathrm{kHz})$; (3) the duty cycle (C, in \%); (4) the AuNPs precursor concentration $\left(\mathrm{D}\right.$, in $\left.\mu \mathrm{g} \mathrm{mL}{ }^{-1}\right)$. The response surface design in the Box-Behnken geometry included 
twenty-seven randomized experimental treatments at three different levels (coded as " -1 ", " 0 " and " +1 ") of the studied operating parameters, counting three center points for which all the operating parameters were set at the central " 0 " level. The boundary levels " 1 " and " +1 " of the operating parameters were arbitrary selected based on the ranges within which the reaction-discharge system was stably operated, i.e., $4.0-6.0 \mathrm{~mL} \mathrm{~min}^{-1}$ in the case of $\mathrm{A}, 0.7-2.3 \mathrm{kHz}$ in the case of $\mathrm{B}, 30-70 \%$ in the case of $\mathrm{C}$, and $50-200 \mu \mathrm{g} \mathrm{mL}^{-1}$ in the case of D.

The responses of the system were: (1) the $\lambda_{\max }$ of the LSPR absorption band of the resultant raw-AuNPs, and (2) their average size corresponding to the $\mathrm{D}_{\mathrm{H}}$ as measured by DLS (see section "The characterization of the raw-AuNPs" for more details). All the experimental treatments within the mentioned response surface design were carried out in one block (Table 1).

The values of the $\lambda_{\max }$ of the LSPR absorption band and the $\mathrm{D}_{\mathrm{H}}$ of the raw-AuNPs were modeled using a full quadratic function that included the main and quadratic effects of the operating parameters as well as their two-way interactions. To reduce the dimensionality of the models, and to facilitate the interpretation of the effects of the operating parameters, the forward selection of terms algorithm with $\alpha$ equal to 0.15 was used to find the regression equations modeling the both responses, i.e., the $\lambda_{\max }$ and the $\mathrm{D}_{\mathrm{H}}$. The ANOVA test was applied to determine the accuracy of the models (one for the $\lambda_{\max }$, the second one for the $\mathrm{D}_{\mathrm{H}}$ ) in fitting the experimental data. Here, the model summary statistics, including the $p$-values for the model and the terms included in it, and the $\mathrm{R}^{2}$ and $\mathrm{S}$ values, were considered and used to assess the reliability of the model. The models were also tested using the lack-of-fit test that provided the evidence of the models adequacy in explaining the measured responses of the pm-rf-APGD-based reaction-discharge system. Finally, the residuals established for the both models, indicating the differences between the measured responses $\left(\lambda_{\max }\right.$ and $\left.\mathrm{D}_{\mathrm{H}}\right)$ and their values predicted by the models, were analyzed to assess the quality of the models and their usefulness in optimizing the system by the RSM. This was realized by viewing the normal probability plots, the histograms of the distribution of the standardized residuals, and the scatter plots of the standardized residuals versus the fitted values and the run order. All of these graphs were useful in discovering any outliers and the non-normality in the distributions of the residuals, and making the final decision about the acceptance of the models.

Next, the models were applied to find the optimal experimental conditions of the pm-rfAPGD-based reaction-discharge system that enabled to produce the smallest and the largest AuNPs. The largest raw-AuNPs were recognized to be those with the highest red shift of the LSPR band in the UV-Vis spectra and the highest average size as determined by DLS, while the smallest raw-AuNPs had the highest blue shift of the LSPR band in the UV-Vis spectra and the lowest average size that could reliably be measured by the DLS instrument used, i.e., $0.8 \mathrm{~nm}$.

\section{The Characterization of the Raw-AuNPs}

The optical properties of the raw-AuNPs were assessed using UV-Vis. The solutions containing AuNPs were introduced into a quartz cuvette and placed in a holder of a Jasco V730 spectrophotometer (MD, Easton, USA). The UV-Vis absorption spectra were recorded in the range from 300 to $800 \mathrm{~nm}$ immediately after the pm-rf-APGD treatment of the $\mathrm{AuCl}_{4}{ }^{-}$ solutions. Deionized water was used as a reference sample. 
Dynamic Light Scattering (DLS) was used to determine the $\mathrm{D}_{\mathrm{H}}$ of the raw-AuNPs and their size distribution by number. It was done using a Photocor Complex device (Photocor Instruments, Tallin, Estonia) equipped with a $657.04 \mathrm{~nm} / 36 \mathrm{~mW}$ laser. The solutions containing the raw-AuNPs were introduced into round vials and submerged in decalin. The data were collected at a scattering angle of $90^{\circ}$ at $21.8{ }^{\circ} \mathrm{C}$, and then analyzed with the DynaLS software (Alango Ltd., Tirat Carmel, Israel). The size distribution by number was established as the mean value for 5 independent measurements.

\section{Preparation of the Nanoemulsion Carrying the Raw-AuNPs}

At first, $4 \mathrm{~mL}$ of a $1.5 \%(\mathrm{w} / \mathrm{v})$ water solution of gelatin $\left(\mathrm{Mw}=80,0000 \mathrm{~g} \mathrm{~mol}^{-1}\right.$, Rousselot International, Dubuque, IA, USA) was prepared. Next, this solution was mixed with the colloidal suspension of the pm-rf-APGD-synthesized raw-AuNPs at a volume ratio 1:2. Simultaneously, turmeric oil (Hemani Live Natural, Dubai, UAE) was added to the resulting mixture ( $0.020 \mathrm{~g}$ of oil), to obtain nanoemulsion. The final concentrations of AuNPs, gelatin, and turmeric oil in the prepared mixture were $133 \mu \mathrm{g} \mathrm{mL} \mathrm{m}^{-1}, 0.5 \%(\mathrm{w} / \mathrm{v})$, and $0.17 \%$ $(\mathrm{w} / \mathrm{v})$, respectively.

\section{The Characterization of the AuNPs-Loaded Nanoemulsion}

The optical properties of the AuNPs-loaded nanoemulsion were assessed using UV-Vis absorption spectrophotometry as described in the section "The characterization of the raw-AuNPs".

The structural properties of the AuNPs loaded into the nanoemulsion were investigated using scanning electron microscopy (SEM) and transmission electron microscopy (TEM) supported by energy dispersive X-ray scattering (EDX) and selected are electron diffraction (SAED), respectively. The SEM analysis was carried out on a Hitachi S-3400 N SEM instrument (Japan) equipped with a Thermo Scientific Ultra Dry EDAX system (USA). The TEM analysis was made with the aid of a Hitachi H-800 TEM instrument (Japan) equipped with 11 Mpix CCD Olympus Quemesa camera. The average size distribution based on the TEM analysis was carried out using the ImageJ software, by measuring 724 nanostructures.

Attenuated total reflectance Fourier-transform infrared spectroscopy (ATR FT-IR) was used to find out whether the AuNPs were functionalized by the nanoemulsion components. The corresponding spectra were acquired using a Vertex 70v FTIR spectrophotometer (Bruker, Bremen, Germany).

\section{Evaluation of the Nanoemulsion Cytotoxicity Towards the Breast Cancer Cell Lines}

\section{Cell Culture Conditions and the Experimental Groups}

The human cancer cell lines MCF7 (ATCC ${ }^{\circledR}$ HTB-22 ${ }^{\mathrm{TM}}$, non-invasive breast cancer cells) and MDA-MB-231 (ATCC ${ }^{\circledR}$ HTB-26 $^{\mathrm{TM}}$, invasive breast cancer cells) were obtained from ATCC, and used to test the biological activity of the AuNPs-loaded nanoemulsion. As a control, the MCF10A cell line (ATCC ${ }^{\circledR}$ CRL-10317TM, non-transformed breast cells) was used. The cell lines were cultured at $37{ }^{\circ} \mathrm{C}$ in an incubator under the $5 \% \mathrm{CO}_{2}$ and $95 \%$ air atmosphere. The cells were maintained in the Opti-MEM 
with GlutaMAX (Thermo Fisher Scientific Inc., USA) medium supplemented with a $2 \%$ fetal bovine serum (FBS, Gibco, UK), a $100 \mathrm{U} \mathrm{mL}^{-1}$ penicillin solution and a $100 \mu \mathrm{g} \mathrm{mL}^{-1}$ streptomycin solution (Sigma-Aldrich, Steinheim, Germany). In the routine cell culture, the MCF7 cells were supplemented with insulin (at $10 \mu \mathrm{g} \mathrm{mL}^{-1}$ ), while the MCF10A cells-with EGF (at $20 \mu \mathrm{g} \mathrm{mL}^{-1}$ ), insulin (at $10 \mu \mathrm{g} \mathrm{mL} \mathrm{m}^{-1}$ ), ECGS (at $50 \mu \mathrm{g} \mathrm{mL}^{-1}$ ), and hydrocortisone (at $0.5 \mu \mathrm{g} \mathrm{mL}^{-1}$ ). The cells were routinely passaged using a $0.05 \%$ trypsin $/ 0.02 \%$ EDTA (w/v) solution.

In order to evaluate the effect of the AuNPs on the cancer and non-transformed cell lines, the cells were treated with different agents, i.e., the nanoemulsion compounds (for groups II, III, IV and VII) or with a solution of the $\mathrm{AuCl}_{4}{ }^{-}$ions (group I) or the colloidal suspension of the raw-AuNPs (group V) and the AuNPs-loaded nanoemulsion (group VI) for $24 \mathrm{~h}$. The concentration of $\mathrm{Au}$ in the groups I, V and VI was previously determined using flame atomic absorption spectrometry (FAAS) after the initial wet digestion of the respective samples in aqua regia. For all the investigated agents containing $\mathrm{Au}$ (groups I, V and VI), the $\mathrm{IC}_{50}$ was assessed using the MTT tests. In all the subsequent MTT tests and the apoptosis assays, the concentration of Au in the examined agents was $25 \mu \mathrm{g} \mathrm{mL}^{-1}$, while the concentration of $10 \mu \mathrm{g} \mathrm{mL} \mathrm{m}^{-1}$ of $\mathrm{Au}$ was used for the scratch test. As a control, the culture medium with neither Au species nor supplements was used for $24 \mathrm{~h}$ (control group). The details of all the agents/compounds used in the in vitro tests are given in Table 2.

\section{MTT Assay}

The cells were seeded in the 96-well plates at a concentration of $2 \times 10^{5}$ cells/well in the dedicated culture medium. The next day, the cells were treated with $25 \mu \mathrm{g} \mathrm{mL} \mathrm{m}^{-1}$ of $\mathrm{Au}$ (for groups I, V and VI) in the medium without serum (Opti-MEM). After $24 \mathrm{~h}$, the cells were washed with PBS twice, followed by the addition of $100 \mu \mathrm{L}$ of a MTT solution $\left(0.4 \mathrm{mg} \mathrm{mL}^{-1}\right.$ of MTT) for the reaction for $3 \mathrm{~h}$ in the dark at $37{ }^{\circ} \mathrm{C}$. Then, the MTT solution was removed, and $100 \mu \mathrm{L}$ of DMSO was added to each well and incubated at $37{ }^{\circ} \mathrm{C}$ for $10 \mathrm{~min}$ to dissolve the purple crystals. The absorbance was measured at $570 \mathrm{~nm}$ with a Victor 2 multi-function microplate reader (Perkin Elmer, USA). The cell viability was calculated as the mean value of the absorbance acquired in triplicates in three independent experiments.

Table 2 The group of the agents/compounds used in the in vitro tests

\begin{tabular}{ll}
\hline Name of the group & Treatment \\
\hline Control & Cells treated with a culture medium alone \\
Group I & Cells treated with a solution of the $\mathrm{AuCl}_{4}^{-}$ions \\
Group II & Cells treated with the pm-rf-APGD-activated water \\
Group III & Cells treated with an aqueous solution of gelatin \\
Group IV & Cells treated with turmeric oil dispersed in water \\
Group V & Cells treated with the colloidal suspension of the raw-AuNPs \\
Group VI & Cells treated with the nanoemulsion carrying the AuNPs \\
Group VII & Cells treated with turmeric oil dispersed in an aqueous solution of gelatin \\
\hline
\end{tabular}




\section{Apoptosis Analysis}

The apoptosis was measured by flow cytometry using an eBioscience ${ }^{\mathrm{TM}}$ Annexin V Apoptosis Detection Kit APC (Invitrogen) to assess the number of the late apoptotic, early apoptotic, and necrotic cells by propidium iodide (PI) in all the groups compared to the control cells treated only with the culture medium alone. Briefly, the cells were cultured in the medium containing serum in the 48-well plates. After reaching the 80-90\% confluence, the studied agents (see details in Table 4) at the Au concentration of $25 \mu \mathrm{g} \mathrm{mL}{ }^{-1}$ were added to each well, and the cells were incubated for further $24 \mathrm{~h}$. Annexin V and PI were then added to each sample according to the manufacturer's instructions. The early apoptotic cells (Annexin V positive, PI negative), late apoptotic cells (Annexin V positive, PI positive), necrotic cells (Annexin V negative, PI positive) and alive cells (Annexin V negative, PI negative) were detected using the FL4 $\left(\lambda_{\mathrm{em}}=660 \mathrm{~nm}\right)$ and FL2 $\left(\lambda_{\mathrm{em}}=535 \mathrm{~nm}\right)$ modes. The data were analyzed using a FACSCalibur flow cytometer (Becton-Dickinson, USA). The percentage of the apoptotic cells was calculated using the Flowing Software 2 program. All the values were presented as the mean \pm SD values for three independent experiments, each consisting of the technical triplicates. The results were analyzed through the unpaired t-tests using the GraphPad Prism 5 software. The p-values for all the investigated groups were calculated compared to the control group (the cells treated with the medium alone).

\section{Scratch Test}

The human cell lines were seeded in the 48-well plates with each well containing $2 \times 10^{5}$ cells in the Opti-MEM medium. After the cell adhesion, the studied agents (see details in Table 4) were added to each well, and the cells were incubated for further $24 \mathrm{~h}$. The final concentration of $\mathrm{Au}$ was reduced to $10 \mu \mathrm{g} \mathrm{mL} \mathrm{m}^{-1}$ in order to investigate migratory effect of alive cells. Next, the cells were washed twice in PBS and a scratch area was formed by scratching with a $10 \mu \mathrm{L}$ tip and the residual cells were washed twice with PBS. Then, the photographs were taken by an optical microscope at $0 \mathrm{~h}$ and after the incubation for $24 \mathrm{~h}$, which were subjected to the analysis by using the ImageJ software. The cell migration area on the both sides was calculated based on the difference between the whole area and the middle scratch area (the relative scratch area). The migration rate over the 24 -h period was calculated by dividing the cell migration area after $24 \mathrm{~h}$ of the treatment by that at $0 \mathrm{~h}$. The results were analyzed through the unpaired t-tests using the GraphPad Prism 5 software. The $p$-values for all the investigated groups were calculated compared to the control group (the cells treated with the medium alone).

\section{Results and Discussion}

\section{Response Surface Regression Models for the $\lambda_{\max }$ of the LSPR Absorption Band of the Synthesized Raw-AuNPs and Their $D_{H}$ as Measured by DLS}

Response surface regression models were developed for both the (1) optical and (2) granulometric properties of the resultant raw-AuNPs. These parameters were collected either by 
determining the $\lambda_{\max }$ of the LSPR absorption band (as determined by UV-Vis absorption spectrophotometry) or by the $\mathrm{D}_{\mathrm{H}}$ of the raw-AuNPs (as determined by DLS).

The quality of the both responses acquired according to the Box-Behnken surface response design was verified. The mean values of the $\lambda_{\max }$ of the LSPR absorption band of the raw-AuNPs and their $\mathrm{D}_{\mathrm{H}}$ were viewed versus the run order. The mean values of the both responses versus their standard deviations were also considered. In the both cases, no trends were found in the resultant scatter plots. In addition, the differences in the both responses between the treatments were higher than the variability of these responses within the treatments. This particularly pointed out that the both responses acquired for the studied reaction-discharge system, i.e., the $\lambda_{\max }$ of the LSPR absorption band of the synthesized raw-AuNPs and their $\mathrm{D}_{\mathrm{H}}$, were varied due to the changes in the operating parameters. Therefore, the both responses were not transformed to stabilize their variance observed during the operation of the studied reaction-discharge system [31,33]. Next, the experimental data for the $\lambda_{\max }$ of the LSPR absorption band of the synthesized raw-AuNPs and their $\mathrm{D}_{\mathrm{H}}$ (the means for 3 repetitions) were fitted with the full quadratic regression models. The number of the possible terms in the response surface regression equations was reduced by using the forward-selection-of-terms algorithm. Accordingly, the developed response surface regression model for the $\lambda_{\max }$ was given by the following equation (Eq. 1):

$$
\begin{aligned}
\lambda_{\max }(\text { in nm })= & 514.2+1.00 \mathrm{~A}+6.93 \mathrm{~B}+2.12 \times 10^{-1} \mathrm{C}+1.45 \times 10^{-1} \mathrm{D}-3.00 \mathrm{~B}^{2} \\
& -1.83 \times 10^{-3} \mathrm{CD} .
\end{aligned}
$$

In the case of the size of the synthesized raw-AuNPs, corresponding to the $\mathrm{D}_{\mathrm{H}}$, the response surface regression model was given by the following equation (Eq. 2):

$$
\begin{aligned}
\mathrm{D}_{\mathrm{H}}(\text { in nm })= & -9.65+2.22 \times 10^{-1} \mathrm{~B}+3.41 \times 10^{-1} \mathrm{C}-1.05 \times 10^{-2} \mathrm{D}-5.24 \times 10^{-1} \mathrm{~A}^{2} \\
& -1.00 \mathrm{~B}^{2}-2.96 \times 10^{-3} \mathrm{C}^{2}-1.33 \times 10^{-4} \mathrm{D}^{2}+8.05 \times 10^{-1} \mathrm{AB}+1.29 \times 10^{-2} \mathrm{AD} \\
& -3.77 \times 10^{-4} \mathrm{CD} .
\end{aligned}
$$

The reliability of the both response surface regression models was tested with the aid of the analysis-of-variance (ANOVA) test and the lack-of-fit test. The results of these tests are given in Tables 3 and 4, respectively, for the $\lambda_{\max }$ and the $\mathrm{D}_{\mathrm{H}}$.

In the case of the response surface regression model for the $\lambda_{\max }$ of the LSPR absorption band of the raw-AuNPs synthesized using the continuous-flow reaction-discharge system proposed in the present work, the linear terms A $(p=0.000), \mathrm{B}(p=0.058)$, and $\mathrm{C}(p=0.110)$, in addition to the non-linear terms, i.e., $\mathrm{B}^{2}(p=0.019)$ and $\mathrm{CD}(p=0.005)$, were statistically significant because the $p$ values for them were lower than $\alpha=0.15$. The statistically insignificant term D $(p=0.511)$ was however included in the equation Eq. 1 of the model because of the hierarchy of the terms. The R-squared $\left(\mathrm{R}^{2}\right)$ value for this model, showing its goodness-of-fit, was $81.6 \%$ and indicated that there was a quite high closeness of the experimental data with the data fitted by the model; almost $82 \%$ of the total variance in the acquired experimental data was explained with the developed response surface regression equation Eq. 1. The adjusted ( $\mathrm{R}^{2}$ adjusted) and predicted ( $\mathrm{R}^{2}$ predicted) R-squared values were also high, i.e., 76.0 and $67.0 \%$, respectively, showing that the mentioned model had a high power for explaining the measured data and predicting the completely new data. The $p$ value calculated for the lack-of-fit test $(p=0.884)$ was much higher than $\alpha=0.15$ taken, hence, the model was certainly statistically significant. The standard error of the regression (S) was also relatively low, while the inspection of the residuals (see Fig. 2a) let to the conclusion that the goodness-of-fit of the response surface regression 
Table 3 The ANOVA test table for the response surface regression model of the $\lambda_{\max }$ of the LSPR absorption band of the uncoated AuNPs synthesized by using the reaction-discharge system with pm-rf-APGD generated in contact with the FLE solution containing the AuNPs precursor

\begin{tabular}{lrrrrr}
\hline Source of data & $D F$ & Adjusted SS & Adjusted MS & $F$ value $^{\mathrm{a}}$ & $p$ value $^{\mathrm{b}}$ \\
\hline Model & 6 & 263.18 & 43.86 & 14.75 & 0.000 \\
Linear & 4 & 213.67 & 53.42 & 17.96 & 0.000 \\
A & 1 & 12.00 & 12.00 & 4.03 & 0.058 \\
B & 1 & 8.33 & 8.33 & 2.80 & 0.110 \\
C & 1 & 1.33 & 1.33 & 0.45 & 0.511 \\
D & 1 & 192.00 & 192.00 & 64.56 & 0.000 \\
Square & 1 & 19.27 & 19.27 & 6.48 & 0.019 \\
B & 1 & 19.27 & 19.27 & 6.48 & 0.019 \\
2-Way interactions & 1 & 30.25 & 30.25 & 10.17 & 0.005 \\
CD & 1 & 30.25 & 30.25 & 10.17 & 0.005 \\
Error & 20 & 59.48 & 2.97 & & 0.41 \\
Lack-of-fit & 18 & 46.82 & 2.60 & & 0.884 \\
Pure error & 2 & 12.67 & 6.33 & & \\
Total & 26 & 322.67 & & & \\
\hline
\end{tabular}

$p$ values $<0.15$ are given in italics

${ }^{\text {a }}$ The value of the $F$ test for the comparison of the model variance with the residual variance

${ }^{\mathrm{b}}$ The forward-selection-of-terms algorithm was used, $\alpha$ to enter equal to 0.15 . LSPR-The localized surface plasmon resonance. pm-rf-APGD-Pulse-modulated radio-frequency atmospheric pressure glow discharge. FLE-The flowing liquid electrode. DF-Degrees of freedom in the source. SS-The sum of squares due to the source. MS-The mean of squares due to the source. A-The flow rate of the FLE solution (in $\mathrm{mL} \min ^{-1}$ ). B-The frequency of the pulse modulation of the rf current (in $\mathrm{kHz}$ ). C-The duty cycle (in $\%)$. D-The AuNPs precursor concentration (in $\mu \mathrm{g} \mathrm{mL}^{-1}$ )

model to the measured values of the $\lambda_{\max }$ was high, confirming the correctness and appropriateness of the developed model for the optimization of the system. Accordingly, the distribution of the standardized residuals had no signs of the non-normality, the standardized residuals were randomly placed on the both sides of the " 0 " axis, falling rather a symmetric pattern with a more or less constant spread throughout the range of the fitted values or the run order.

In the case of the response surface regression model for the average $\mathrm{D}_{\mathrm{H}}$ of the rawAuNPs, the following non-linear terms were statistically significant in the response surface regression equation Eq. 2: $\mathrm{A}^{2}(p=0.040), \mathrm{B}^{2}(p=0.001), \mathrm{C}^{2}(p=0.000), \mathrm{D}^{2}(p=0.006)$, and $\mathrm{AB}(p=0.030), \mathrm{AD}(p=0.003)$, as well as $\mathrm{CD}(p=0.053)$. All the linear terms, i.e., $\mathrm{A}, \mathrm{B}, \mathrm{C}$, and $\mathrm{D}$, were statistically insignificant $(p>\alpha=0.15)$, but they were kept in the regression equation because of the hierarchy of the terms. The goodness-of-fit of the established response surface regression model, as represented by the $\mathrm{R}^{2}$ value of $79.6 \%$, was also high. The $\mathrm{R}^{2}$ adjusted and predicted values (64.6 and $36.3 \%$, respectively) were fair but not as high as in the case of the $\mathrm{R}^{2}$ statistics for the model of the $\lambda_{\max }$. Nevertheless, the $p$-value $(p=0.247)$ for the lack-of-fit test was higher than $\alpha=0.15$, while the $\mathrm{S}$ value was 0.5 ; hence, there was no reason to reject the model. The inspection of the residuals also confirmed that the developed response surface regression model for the $\mathrm{D}_{\mathrm{H}}$ fitted the experimental data well. The normal probability plot, the histogram of the frequency distribution of the standardized residuals and the scatter-plots of the standardized residuals 
Table 4 The ANOVA test table for the response surface regression model of the average $\mathrm{D}_{\mathrm{H}}$ of the rawAuNPs synthesized by using the reaction-discharge system with pm-rf-APGD generated in contact with the FLE solution containing the AuNPs precursor

\begin{tabular}{lrrlcc}
\hline Source of data & $D F$ & Adjusted SS & Adjusted MS & $F$ value $^{\mathrm{a}}$ & $p$ value $^{\mathrm{b}}$ \\
\hline Model & 11 & 16.95 & 1.54 & 5.31 & 0.002 \\
Linear & 4 & 0.76 & 0.19 & 0.66 & 0.630 \\
A & 1 & 0.44 & 0.44 & 1.50 & 0.239 \\
B & 1 & 0.07 & 0.07 & 0.23 & 0.635 \\
C & 1 & 0.02 & 0.02 & 0.09 & 0.773 \\
D & 1 & 0.24 & 0.24 & 0.82 & 0.381 \\
Square & 4 & 9.49 & 2.37 & 8.19 & 0.001 \\
A $^{2}$ & 1 & 1.46 & 1.46 & 5.04 & 0.040 \\
$\mathrm{~B}^{2}$ & 1 & 4.55 & 4.55 & 15.69 & 0.001 \\
$\mathrm{C}^{2}$ & 1 & 7.48 & 7.48 & 25.81 & 0.000 \\
$\mathrm{D}^{2}$ & 1 & 3.00 & 3.00 & 10.34 & 0.006 \\
2-Way interactions & 3 & 6.69 & 2.23 & 7.69 & 0.002 \\
AB & 1 & 1.66 & 1.66 & 5.73 & 0.030 \\
AD & 1 & 3.75 & 3.75 & 12.92 & 0.003 \\
CD & 1 & 1.28 & 1.28 & 4.41 & 0.053 \\
Error & 15 & 4.35 & 0.29 & & \\
Lack-of-fit & 13 & 4.16 & 0.32 & 3.46 & 0.247 \\
Pure error & 2 & 0.18 & 0.09 & & \\
Total & 26 & 21.30 & & & \\
\hline
\end{tabular}

$p$ values $<0.15$ are given in italics

${ }^{a}$ The value of the $F$ test for the comparison of the model variance with the residual variance

${ }^{b}$ The forward selection of terms algorithm was used, $\alpha$ to enter equal to 0.15 . $\mathrm{D}_{\mathrm{H}}-$ The hydrodynamic particle diameter. pm-rf-APGD-Pulse-modulated radio-frequency atmospheric pressure glow discharge. FLE-The flowing liquid electrode. DF-Degrees of freedom in the source. SS-The sum of squares due to the source. MS-The mean of squares due to the source. A-The flow rate of the FLE solution (in $\mathrm{mL} \mathrm{min}^{-1}$ ). B-The frequency of the pulse modulation of the rf current (in $\mathrm{kHz}$ ). C-The duty cycle (in \%). D-The AuNPs precursor concentration (in $\mu \mathrm{g} \mathrm{mL}^{-1}$ )

versus the fitted values and the run order did not exhibit any unusual structures or patterns (see Fig. 2b). This confirmed the correctness of the model and its usefulness for the optimization of the experimental conditions of the reaction-discharge system for the synthesis of the size-defined surfactant free AuNPs.

\section{The Effect of the Operating Parameters on the $\lambda_{\max }$ of the LSPR Absorption Band of the Synthesized Raw-AuNPs and Their $D_{H}$}

The both responses of the studied pm-rf-APGD-based reaction-discharge system were related to the size of the uncoated AuNPs. The $\lambda_{\max }$ of the LSPR absorption band, as evaluated by UV-Vis absorption spectrophotometry, was indirectly associated with the size of the AuNPs, as based on the Mie theory [12], while the $\mathrm{D}_{\mathrm{H}}$ was directly measured by DLS. Considering the response surface regression models, the effect of the operating parameters $\mathrm{A}, \mathrm{B}, \mathrm{C}$, and D on the $\lambda_{\max }$ of the LSPR absorption band of the raw-AuNPs and their $\mathrm{D}_{\mathrm{H}}$ 
A
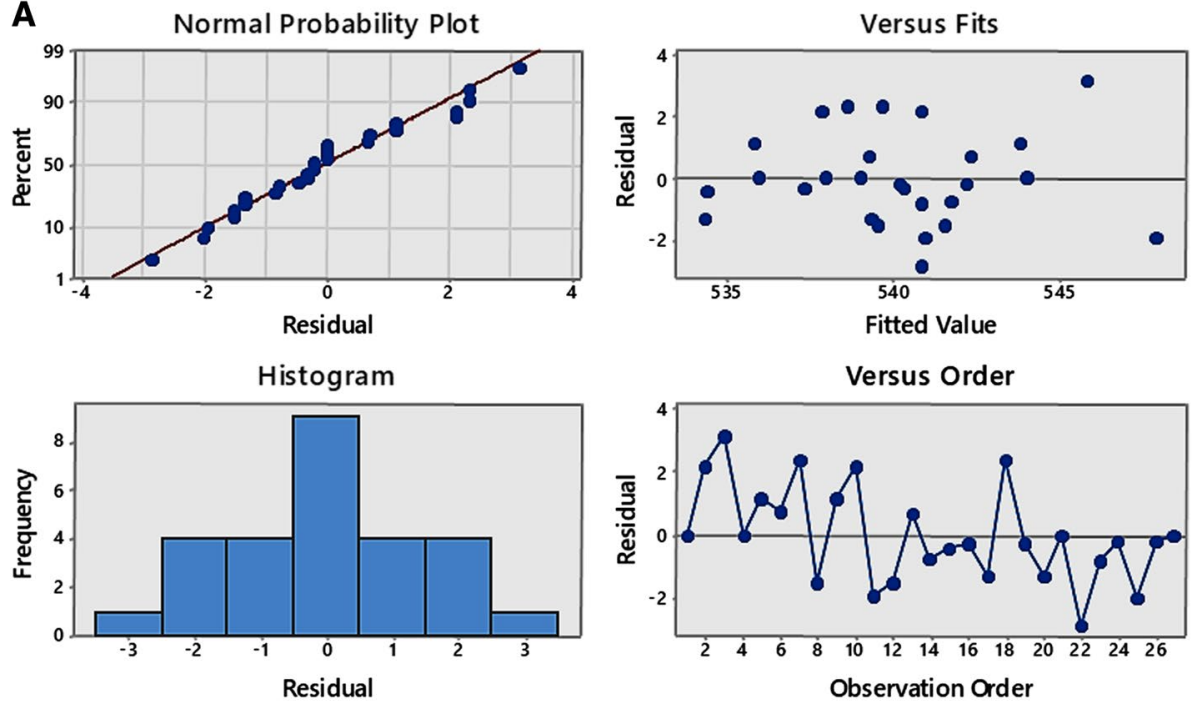

B
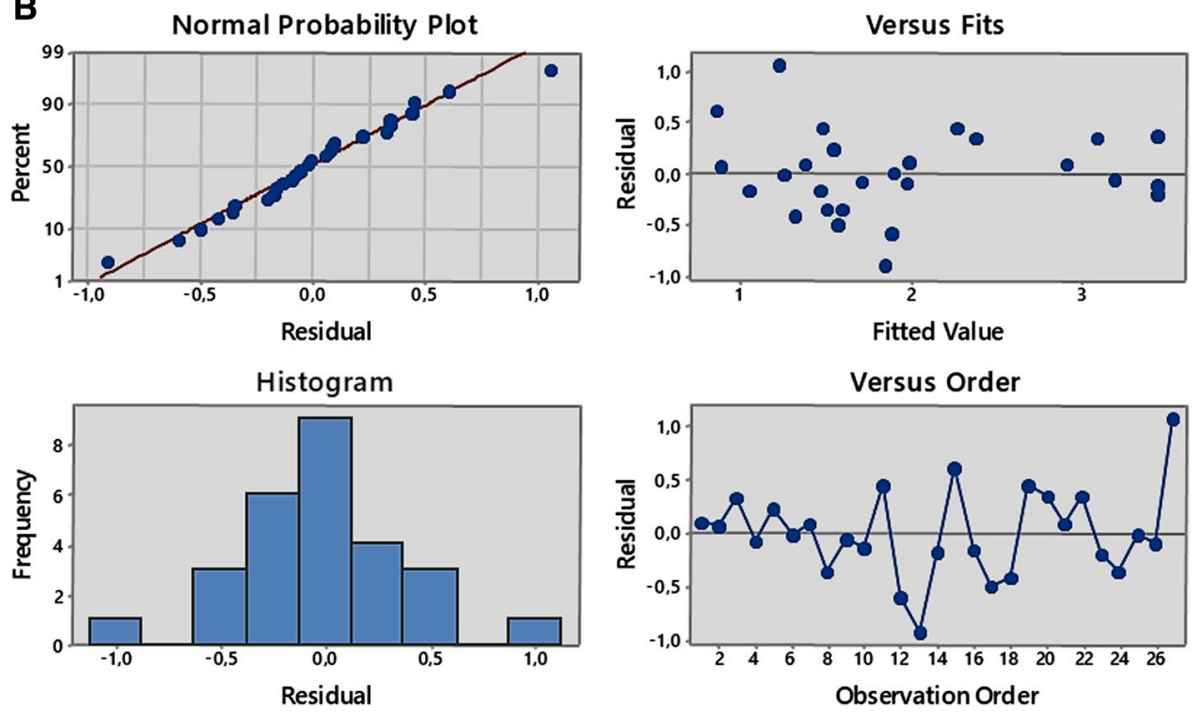

Fig. 2 The distribution of the residuals in the developed response surface regression models (the normal probability plot, the histogram of the frequency distribution of the standardized residuals, the scatter-plots of the standardized residuals versus the fitted value and the run order) for the $\lambda_{\max }$ of the LSPR absorption band of the synthesized uncoated AuNPs (a) and their $\mathrm{D}_{\mathrm{H}}(\mathbf{b})$

(see Fig. 3) was acknowledged similar; however, for the $\lambda_{\max }$ this effect was primarily linear, whereas the squared terms were predominant in the model representing the $\mathrm{D}_{\mathrm{H}}$. In the both response surface regression models, by increasing the flow rate of the FLE solution (the operating parameter A) and the concentration of the AuNPs precursor (the operating parameter D), the raw-AuNPs with a larger size could be synthesized, as manifested by a "red shift" of the $\lambda_{\max }$ of their LSPR absorption band and their higher $\mathrm{D}_{\mathrm{H}}$ values. This was 


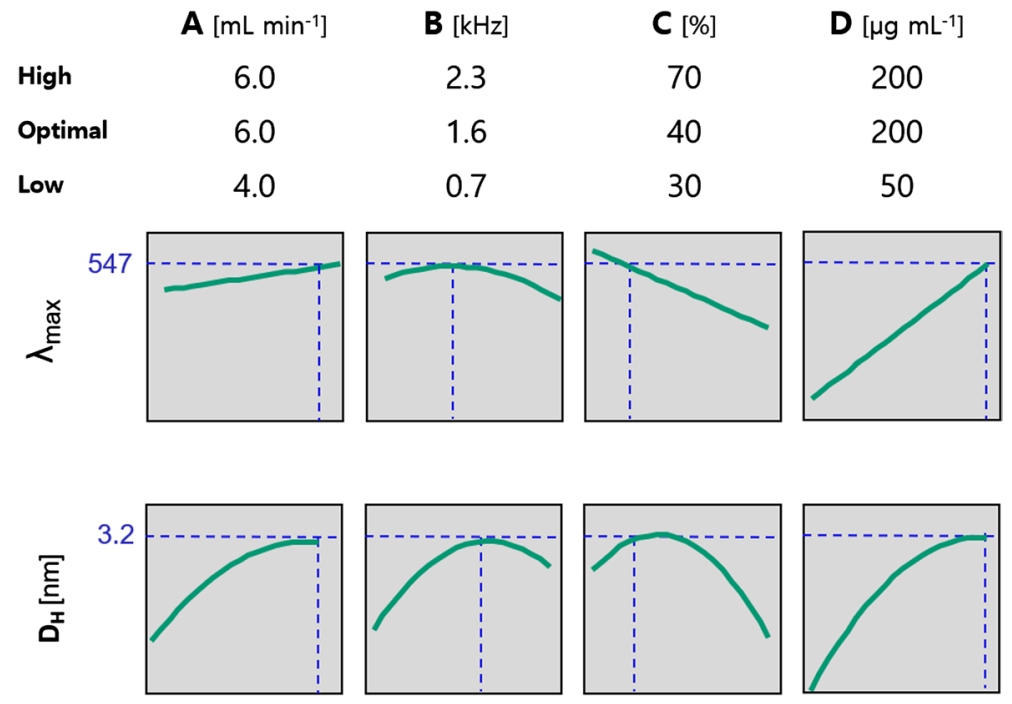

Fig. 3 The graphical representation of the effect of the operating parameters on the responses of the reaction-discharge system with pm-rf-APGD, i.e., the $\lambda_{\max }$ of the LSPR absorption band of the synthesized rawAuNPs and their $\mathrm{D}_{\mathrm{H}}$. A The flow rate of the FLE solution. B The frequency of the pulse modulation of the rf current. C The duty cycle. D The AuNPs precursor concentration

certainly coincident with the increase of the concentration of the $\mathrm{AuCl}_{4}{ }^{-}$ions available for the reduction by the appropriate plasma-liquid interactions-derived reducing agents, e.g., $\mathrm{H}_{2} \mathrm{O}_{2}$ [13-15]. In such conditions, according to the Fike-Watzky two-step mechanism of the nucleation and growth of the Au nanostructures [16], at the higher concentrations of the $\mathrm{AuCl}_{4}{ }^{-}$ions, the growth of the nucleated AuNPs seeds was likely faster because the reduction of the precursor ions could also take place on the surface of the AuNPs that adsorbed these ions. As a result, the larger raw-AuNPs were produced rather than the new nucleation seeds or the small AuNPs were formed in the solution due to the above-mentioned surfaceassisted reduction of the existing nucleated seeds and/or the small AuNPs [13-16].

The increase of the frequency of the pulse modulation of the rf current (the operating parameter B) gave rise to the gradual elevation of the $\lambda_{\max }$ of the LSPR absorption band of the raw-AuNPs and their $\mathrm{D}_{\mathrm{H}}$ up to a certain level, i.e., $1.6 \mathrm{kHz}$. A further growth of the frequency of the pulse modulation of the rf current above this level was responsible for decreasing the both responses. In the case of the duty cycle of the pulse (the operating parameter C), its increase from 30 to $70 \%$ resulted in shifting the $\lambda_{\max }$ of the LSPR absorption band toward the shorter wavelengths (the "blue shift") and lowering the size of the synthesized raw-AuNPs as expressed by the $\mathrm{D}_{\mathrm{H}}$ measured in these conditions. Such behavior of the studied reaction-discharge system with pm-rf-APGD occurred because the both operating parameters $\mathrm{B}$ and $\mathrm{C}$ affected the discharge power associated with the pulse width in the subsequent on-and-off cycles and the duration of the period with the active discharge, advancing the plasma-liquid interactions. The higher discharge power resulted in increasing the production rate of the raw-AuNPs, i.e., the higher formation of the new nucleation seeds rather than the growth of the small AuNPs [12, 14, 17]. However, this was not the only one benefit related to the usage of pm-rf-APGD. The fast interchanges of the polarity of the FLE solution from negative to positive within the pulses were certainly convenient for etching the raw-AuNPs and stabilizing their colloidal structure, 
preventing from the aggregation of the nuclei and agglomeration of the nanostructures. This undoubtedly distinguishes the studied pm-rf-APGD-based reaction-discharge system from other reported so far in the literature [12-30]. All the cited works propose non-flowthrough reaction-discharge systems with dc-driven APGDs generated in contact with the positively polarized solutions, being the example of the plasma cathode and the solution anode, where the surface of the solutions is irradiated with the electrons $\left(\mathrm{e}_{\mathrm{g}}^{-}\right)$coming from the discharge column. Although rf-APGD operated in the atmosphere of Ar in a non-flowthrough system was previously applied for the synthesis of the DNA stabilized AuNPs, the gas pressure had to be reduced in this case just to $40.0 \mathrm{kPa}$ because the plasma-treated solutions were overheated and evaporated [23, 24].

The novelty of the reaction-discharge system proposed in the present study was that pmrf-APGD was sustained at the atmospheric pressure (approximately $101.3 \mathrm{kPa}$ ) and completely operated in the ambient air (no additional gas was needed). The previously reported problem with the overheating of the plasma-treated solutions was solved by using the flowthrough system (the surface of the solution was continuously replenished) and the duty cycle operation that related to the certain discharge activity "on" and "off" times within the rf current pulse period.

Summarizing, aside from its flow-through character and possibility for the continuousflow production of the raw-AuNPs, the uniqueness of the developed reaction-discharge system lied in two additional phenomena that concurrently occurred due to the application of pm-rf-driven APGD. Accordingly, the $\mathrm{pH}$ of the FLE solutions lowered because the surface of the solutions, containing the AuNPs precursor, was bombarded with the $\mathrm{H}_{2} \mathrm{O}_{\mathrm{g}}^{+}$ions when it was negatively polarized within the pulse (see the following reaction: $\left.3 \mathrm{H}_{2} \mathrm{O}+\mathrm{H}_{2} \mathrm{O}_{\mathrm{g}}^{+}=2 \mathrm{H}_{3} \mathrm{O}_{\mathrm{aq}}^{+}+2 \mathrm{OH}^{\bullet}+\mathrm{e}_{\mathrm{aq}}^{-}[13,15]\right)$. In the presence of the formed $\mathrm{H}_{3} \mathrm{O}^{+}$ions and the $\mathrm{Cl}^{-}$ions, released from the $\mathrm{AuCl}_{4}{ }^{-}$ions during their reduction [14], the resulting raw-AuNPs were etched to make their colloidal structure lower-sized and more monodispersed. Concurrently, when the surface of the FLE solutions was bombarded by the $\mathrm{e}_{\mathrm{g}}^{-}$during its positive polarization within the pulse, the very large amounts of the charge were transferred to the solution [12-14]. The $\mathrm{e}_{\mathrm{g}}^{-}$that did not participate in the production of $\mathrm{H}_{2} \mathrm{O}_{2}$ molecules, i.e., $\mathrm{e}_{\mathrm{g}}^{-}+\mathrm{H}_{2} \mathrm{O}=\mathrm{OH}^{\bullet}+\mathrm{H}^{-}, 2 \mathrm{OH}^{\bullet}=\mathrm{H}_{2} \mathrm{O}_{2}$, likely interacted with the rawAuNPs, which could have captured them, and contributed to the formation of a negative charge on their surface [13]. Hence, the electrostatic stabilization of the colloidal structure of the synthesized surfactant free AuNPs was provided in these conditions by the Coulomb repulsions in the solution [13].

\section{Size-Controlled Synthesis of the Raw-AuNPs}

On the basis of the developed response surface response regression models for the $\lambda_{\max }$ and the $\mathrm{D}_{\mathrm{H}}$, the operating parameters of the reaction-discharge system with pmrf-APGD were selected to provide the electrostatically stable raw-AuNPs with the largest and the smallest size. In the case of the largest raw-AuNPs, it was established that the following parameters should be applied for the synthesis: the flow rate of the FLE solution (A) $-6.0 \mathrm{~mL} \mathrm{~min}{ }^{-1}$, the frequency of the pulse modulation of the rf discharge current (B) $-1.6 \mathrm{kHz}$, the duty cycle (C) - 40\%, and the AuNPs precursor concentration (D) $-200 \mu \mathrm{g} \mathrm{mL}^{-1}$ (see Fig. 3). According to the both developed models, the synthesized in these experimental conditions AuNPs would be characterized by the $\lambda_{\max }$ of their LSPR absorption band of $547 \pm 1 \mathrm{~nm}$ and have the $D_{H}$ of $3.2 \pm 0.4 \mathrm{~nm}$. To verify the accuracy of the both models and the correctness of the selection of the optimal 
conditions for the synthesis of the largest raw-AuNPs, the examined reaction-discharge system was run under the selected operating parameters. The resultant pm-rf-APGDtreated solutions, containing the synthesized raw-AuNPs, were collected and analyzed by UV-Vis absorption spectrophotometry and DLS. In five independently repeated experiments, it was established that the raw-AuNPs produced in these conditions exhibited the $\lambda_{\max }$ of the LSPR absorption band at $552 \pm 1 \mathrm{~nm}$ and had the $\mathrm{D}_{\mathrm{H}}$ of $3.2 \pm 0.4 \mathrm{~nm}$ as displayed in Fig. 4a.

In a similar way, it was ascertained that the following operating parameters would provide the raw-AuNPs exhibiting the $\lambda_{\max }$ of their LSPR absorption band at $532 \pm 1 \mathrm{~nm}$ and the $\mathrm{D}_{\mathrm{H}}$ of $0.8 \pm 0.5 \mathrm{~nm}: \mathrm{A}-4.0 \mathrm{~mL} \mathrm{~min}^{-1}, \mathrm{~B}-2.2 \mathrm{kHz}, \mathrm{C}-35 \%$, and $\mathrm{D}-50 \mu \mathrm{g} \mathrm{mL}{ }^{-1}$. Again, the studied reaction-discharge system was used to synthesize the raw-AuNPs under these conditions, and the collected plasma-treated solutions were subjected to the analysis by UV-Vis absorption spectrophotometry and DLS. The synthesized nanomaterial had the $\lambda_{\max }$ of the LSPR absorption band at $535 \pm 4 \mathrm{~nm}$ and the $\mathrm{D}_{\mathrm{H}}$ of $0.8 \pm 0.6 \mathrm{~nm}$ (Fig. $4 \mathrm{~b}$ ). The both measures confirmed the usefulness of the RSM approach to reliably find the operating parameters for the size-controlled synthesis of raw-AuNPs with the aid of the studied pm-rf-APGD-based reaction-discharge system. The proposed methodology was also found to be useful for the continuous-flow
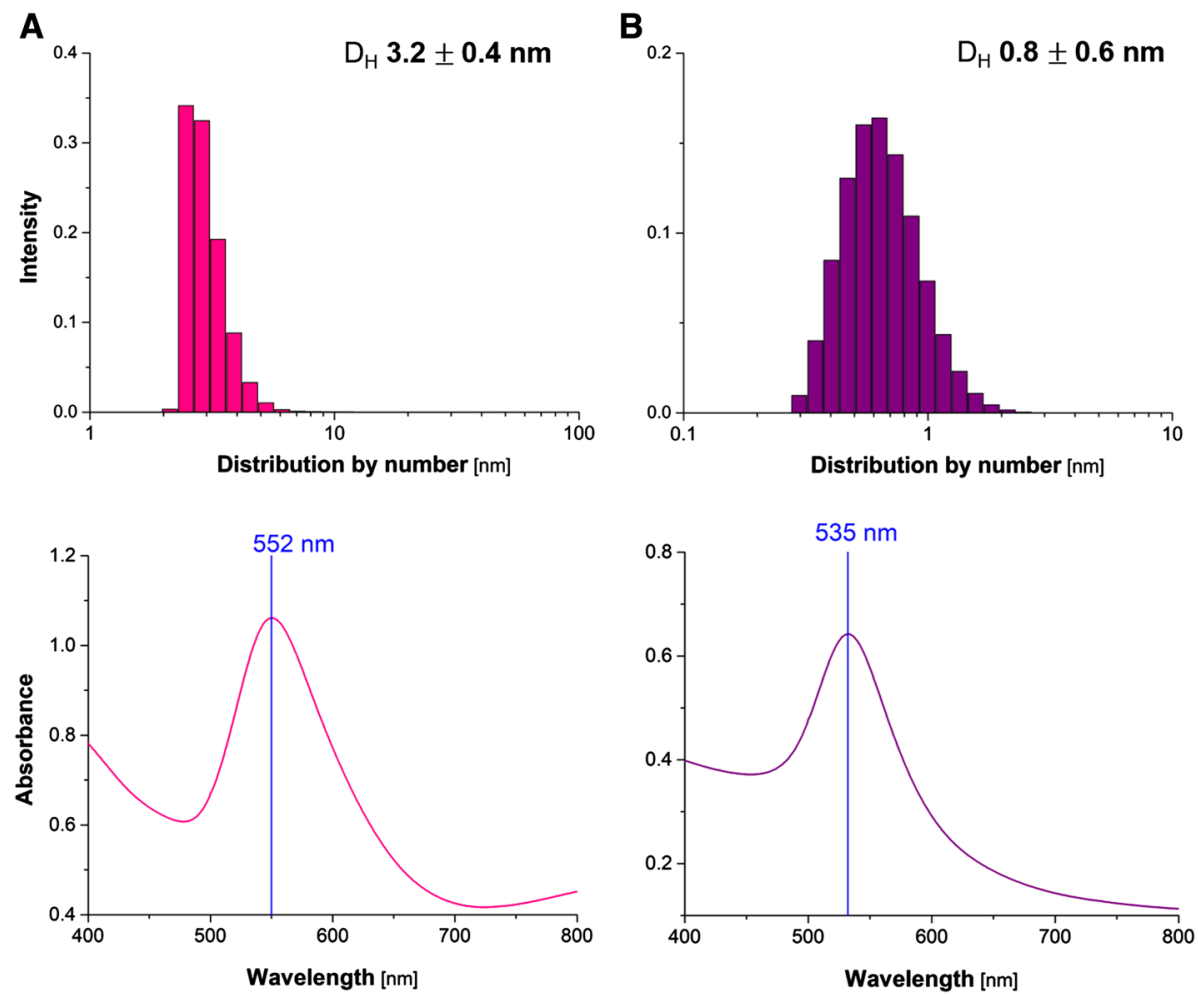

Fig. 4 The average size distribution and the UV-Vis absorption spectra recorded for $\mathbf{a}$ the largest and $\mathbf{b}$ the smallest raw-AuNPs synthesized by using the studied reaction-discharge system with pm-rf-APGD generated in contact with the FLE solution 
synthesis of the pectin-stabilized AgNPs, exhibiting the cytotoxicity towards the human melanoma cancer cells [54].

\section{The Optical and Structural Properties of the AuNPs Colloidal Suspension Loaded into Nanoemulsion}

The $\mathrm{Au}$ nanostructures colloidal suspension obtained under the operating parameters for the production of the largest nanostructures were immediately loaded into an $\mathrm{O} / \mathrm{W}$ nanoemulsion consisting of turmeric oil and a gelatin aqueous solution. The raw-AuNPs contained in the mixture were not purified before their loading into the nanoemulsion. The purification process could lead to their aggregation and sedimentation, hence, it was avoided. The optical and structural properties of the AuNPs loaded into the O/W nanoemulsion are presented in Fig. 5.

The $\lambda_{\max }$ of the LSPR absorption band of the AuNPs loaded into the nanoemulsion was located at $566 \mathrm{~nm}$. As compared to the determined $\lambda_{\max }$ of $552 \mathrm{~nm}$ for the largest raw-AuNPs, this was red-shifted, suggesting a slight decrease in the average size of the $\mathrm{Au}$ nanostructure loaded into the nanoemulsion (see Fig. 5a). This could be the effect of gelatin and turmeric oil, which -OH functional groups could stabilize the AuNPs carried by the emulsion formed as reported in Ref. [55] for the Au and Ag nanostructures. To reveal the preliminary structural properties of the AuNPs loaded into the O/W nanoemulsion, the SEM was employed. As can be seen from Fig. 5b, the differentially shaped AuNPs were present in the nanoemulsion. Additionally, the EDX spectroscopy was used to find the elemental composition of the resulted nanoemulsion carrying the Au nanostructures. The EDX spectrum, corresponding to the point labeled as (1) in the SEM photomicrography (see Fig. 5b), confirmed the presence of the metallic Au. Additionally, $\mathrm{C}, \mathrm{O}$, and $\mathrm{N}$, were detected due to the chemical structure of gelatin and turmeric oil. An imperceptible band (barely visible in Fig. 5b), attributed to the presence of $\mathrm{Cl}$ suggested that the conversion of the AuNPs precursor due to the plasma-liquid interactions was almost complete.

To verify the structural properties of the AuNPs loaded into the nanoemulsion, TEM supported by the SAED was also used. As displayed in Fig. 6a, the AuNPs of spherical, and triangular, were found in the nanoemulsion. Based on the all captured photomicrographs their size ranged from 0.5 to $237 \mathrm{~nm}$; however, the majority of the AuNPs did not exceed $10 \mathrm{~nm}$ as shown in the particle size distribution in Fig. 6b. In fact, the mean
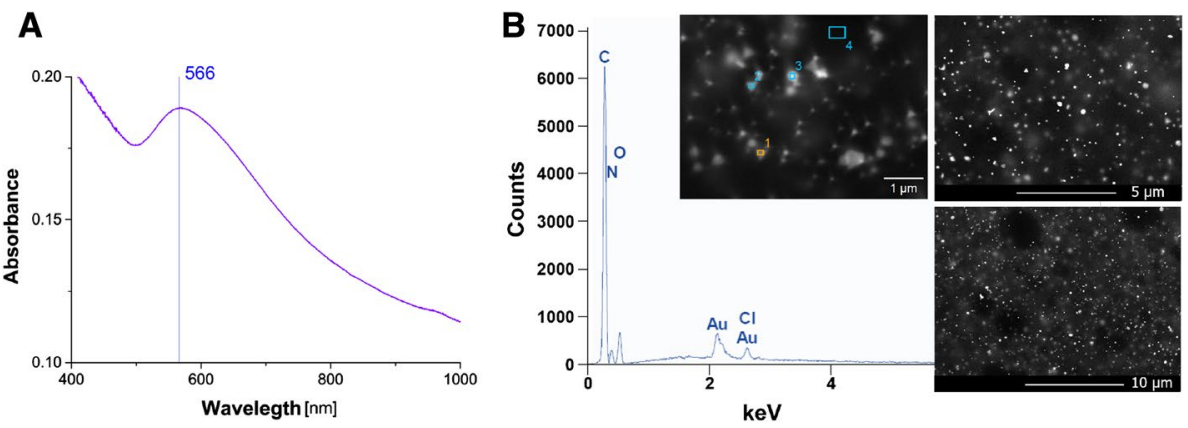

Fig. 5 a The UV-Vis absorption spectrum of the AuNPs-loaded nanoemulsion and b the SEM/EDX photomicrographs thereof 
A

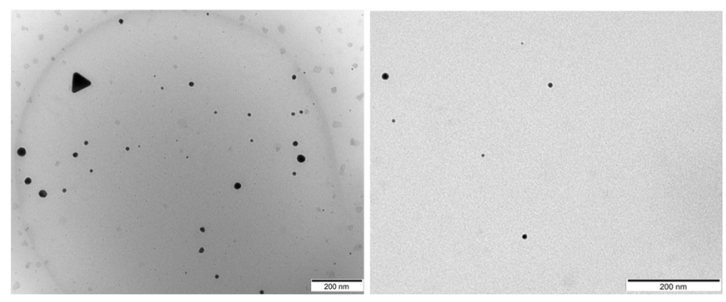

B

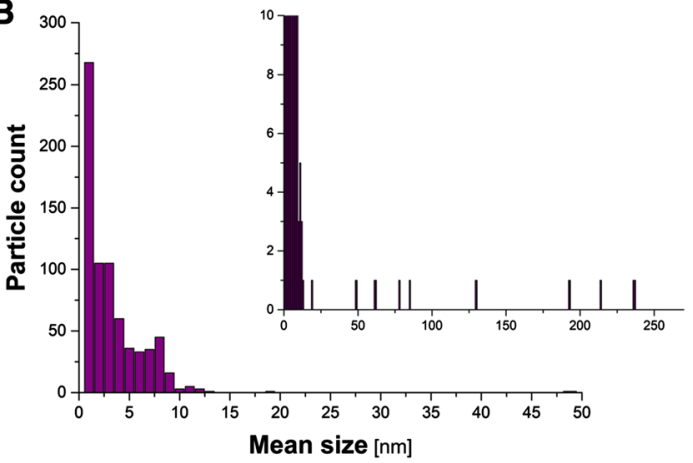

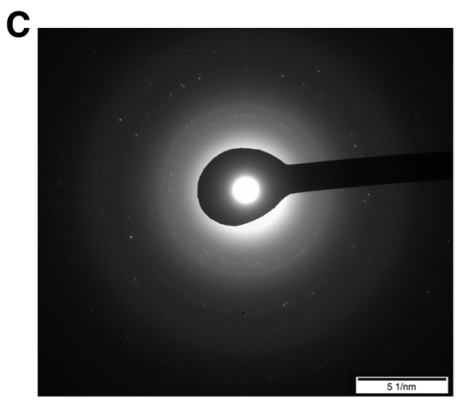

Experimental d-spacing

Ring 1: $2.41 \AA$

Ring 2: $2.07 \AA$

Ring 3: $1.48 \AA$

Ring 4: $1.26 \AA$

Fig. 6 a The TEM photomicrographs, $\mathbf{b}$ the average size of the AuNPs determined based on TEM and $\mathbf{c}$ the SAED pattern recorded for the AuNPs-loaded nanoemulsion

diameter calculated based on 724 nanostructures was $4.6 \pm 1.0 \mathrm{~nm}$. This well corresponded to the size of the raw-AuNPs determined using DLS $(3.2 \pm 0.4 \mathrm{~nm})$. The SAED pattern displayed in Fig. $6 \mathrm{c}$ allowed to define the d-spacings of the analyzed nanostructures. Their values confirmed that the nanoemulsion indeed contained the face-centered cubic (FCC) crystalline AuNPs [56].

\section{The Surface Functionalization of the AuNPs}

In the next step, an attempt was made to confirm that the loading of the raw-AuNPs into the nanoemulsion had led to the functionalization of their surface by turmeric oil and gelatin. Accordingly, the ATR FT-IR spectra of all the separate components, i.e., gelatin, turmeric oil, raw-AuNPs, and all of the components combined together to form the nanoemulsion were recorded as shown in Fig. 7.

The spectrum of gelatin normally shows a series of the protein vibrations, mainly related to the amide absorptions, generating the bands called Amide A, I, II, and III [57, 58]. Indeed, the intense IR absorptions of the $\nu \mathrm{N}-\mathrm{H}$ (and $\nu \mathrm{O}-\mathrm{H}$ from $\mathrm{H}_{2} \mathrm{O}$ ) stretching vibrations, seen as a broad band at $3313 \mathrm{~cm}^{-1}$ (Amide A band), were identified in the spectrum of a gelatin solution. The $\nu \mathrm{C}=\mathrm{O}$ group stretching vibration, observed as a strong band at $1644 \mathrm{~cm}^{-1}$, was associated with the Amide I band (Fig. 7a). Finally, the medium band at $1534 \mathrm{~cm}^{-1}$ was likely due to the $\nu \mathrm{N}-\mathrm{H}$ bending vibration and with a small contribution of the $\nu \mathrm{C}-\mathrm{N}$ stretching vibration recognized as the Amide II band (Fig. 7a) [59, 60].

The spectrum of turmeric oil contained a weak band at $1744 \mathrm{~cm}^{-1}$ that was attributed to the $\nu \mathrm{C}=\mathrm{O}$ stretching vibrations of the ester groups occurring in natural oil (Fig. 7b). This 

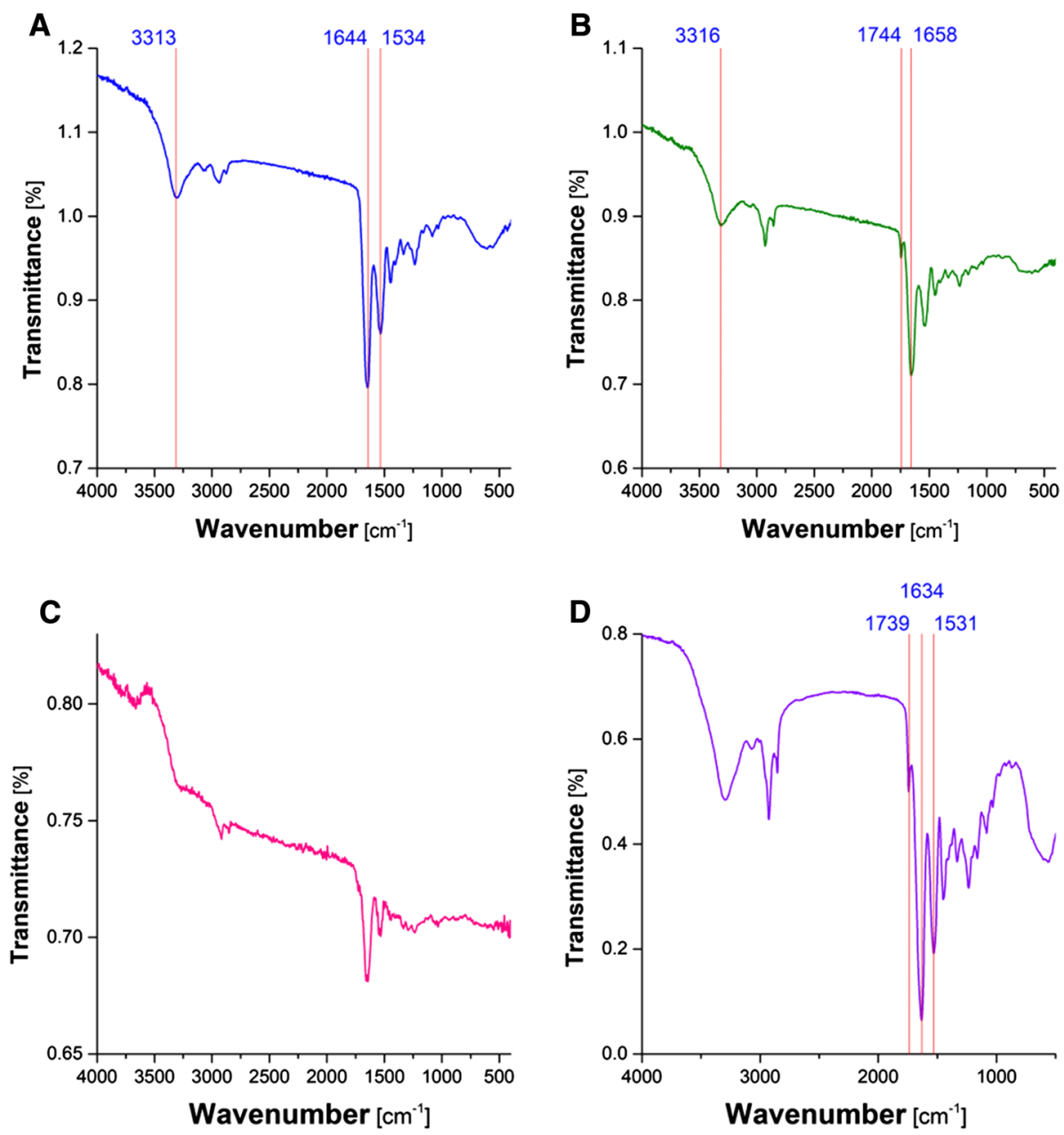

Fig. 7 The ATR FT-IR spectra recorded for the a gelatin, b turmeric oil, c raw-AuNPs, d AuNPs-loaded nanoemulsion

band was also observed in the spectrum of the AuNPs-loaded nanoemulsion, confirming the presence of turmeric oil in the final formulation. Besides, the medium broad band at $3316 \mathrm{~cm}^{-1}$, assigned to the $\nu \mathrm{O}-\mathrm{H}$ stretching vibrations from water and turmeric oil, was also observed (Fig. 7b). Other absorption bands in this spectrum were also characteristic for oils; however, they were shifted as a resulting of the dispersion of turmeric oil in water as reported before [61].

The spectrum of the AuNPs-loaded nanoemulsion displayed some characteristic bands in the fingerprint region coming from gelatin and turmeric oil. However, these bands were shifted to the lower wavenumbers, which likely indicated the formation of the weak hydrogen bonds between the emulsion components and the AuNPs. This primarily included the shift of the strong peaks at $1644 \mathrm{~cm}^{-1}$ (Fig. 7a) and $1658 \mathrm{~cm}^{-1}$ (Fig. $\left.7 \mathrm{~b}\right)(\nu \mathrm{C}=\mathrm{O})$ in the spectra of gelatin and turmeric oil, respectively, to $1634 \mathrm{~cm}^{-1}$ (Fig. 7d) in the spectrum of the nanoemulsion. Furthermore, some small wavenumber differences were found for the 
Amide II bands in gelatin $\left(\sim 3 \mathrm{~cm}^{-1}\right)$ (Fig. $7 \mathrm{a}$ vs. d) and the $\nu \mathrm{C}=\mathrm{C}$ stretching vibrations in turmeric oil $\left(\sim 5 \mathrm{~cm}^{-1}\right)$ (Fig. $7 \mathrm{~b}$ vs. d). These differences suggested that the AuNPs were likely capped by turmeric oil and gelatin. Moreover, as the ATR FT-IR spectra suggested the presence of the weak hydrogen bonds between the AuNPs and turmeric oil and gelatin, it was concluded that the nanoemulsion not only capped the AuNPs but might also functionalized their surface.

\section{Biological Effect of the Nanoemulsion Carrying the Au Nanostructures}

\section{Colorimetric MTT Assay}

The cytotoxic effect of the AuNPs-loaded nanoemulsion (group VI) towards the human breast cancer and non-cancerous cell lines was examined using 3-(4,5-Dimethyl2-thiazolyl)-2,5-diphenyl-2H-tetrazolium bromide (MTT). The AuNPs induced the dosedependent toxicity to the cancer cells. For the non-tumor MCF10A cell line, the half maximal inhibitory concentration $\left(\mathrm{IC}_{50}\right)$ was $>40 \mu \mathrm{g} \mathrm{mL}^{-1}$ of $\mathrm{Au}$. In contrast, for the noninvasive MCF7 cell line the $\mathrm{IC}_{50}$ was around $30 \mu \mathrm{g} \mathrm{mL} \mathrm{m}^{-1}$ of $\mathrm{Au}$, while the $\mathrm{IC}_{50}$ towards

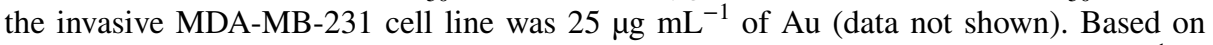
these results, all the cytotoxicity tests were done on the cells treated with $25 \mu \mathrm{g} \mathrm{mL} \mathrm{m}^{-1}$ of $\mathrm{Au}$ in all three groups where $\mathrm{Au}$ was present (groups I, V and VI). A strong inhibition of the proliferation of the invasive MDA-MB-231 breast cancer cells treated with the AuNPsloaded nanoemulsion (group VI) was observed (Fig. 8). In contrast, the proliferation of the non-invasive MCF7 breast cancer cell line was reduced after the treatment of the cells with an $\mathrm{AuCl}_{4}{ }^{-}$solution (group I), however, the proliferation inhibition was not statistically significant. The control non-tumor cell line MCF10A was not sensitive to all the examined groups containing Au. Additionally, for all other groups without Au (groups II, III, IV and VII, see details in Table 2) there were no difference in the absorbance between the investigated groups and the control in all the cell lines. These results showed that AuNPs-loaded nanoemulsion (group VI) could inhibit the proliferation of the invasive breast cancer cells and did not moderate the non-invasive cancer cells as well as the non-transformed breast cells. Similar results were reported by other researchers, who observed the inhibition of the breast cancer cells treated with the AuNPs [62, 63]. However, in our study it was observed that the proliferation activity of the human cancer invasive cells was selectively inhibited
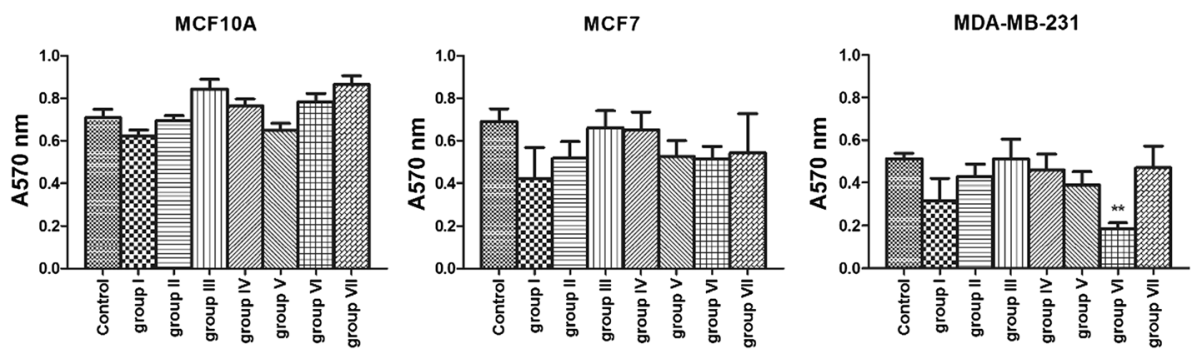

Fig. 8 The proliferation measured as the absorbance at $570 \mathrm{~nm}$ of the human non-transformed breast cell line (MCF10A), non-invasive cancer cell line (MCF7), and invasive cancer cell line (MDA-MB-231) treated with different agents (see the description of the groups given in Table 2). The data are given as the mean \pm SD values for three analyses done in triplicate. The statistical comparison was performed using the unpaired $t$ test and compared to the untreated controls $* * p<0.01$ 
as compared with the proliferation activity of the non-invasive and non-transformed cells after the treatment with the AuNPs-loaded nanoemulsion (group VI for MDA-MB-231 vs. MCF7 and MCF10A cell lines).

\section{Apoptosis Test}

As shown in Fig. 9, the reduction of the viable cells (62\% for MCF7 and 55\% for MDAMB-231; $p<0.05$ and $p<0.01$; respectively) was detected following their treatment with the AuNPs-loaded nanoemulsion (group VI, $25 \mu \mathrm{g} \mathrm{mL} \mathrm{m}^{-1}$ of $\mathrm{Au}$ ) and compared to the control cell population treated only with the culture medium. The majority of the tumor cells underwent the necrosis within $24 \mathrm{~h}$. Similar results were observed when the invasive tumor cells MDA-MB-231 were treated with the $\mathrm{AuCl}_{4}{ }^{-}$ions (group I). No statistically significant apoptosis was detected when the non-transformed breast cells MCF10A were treated with the $\mathrm{AuCl}_{4}{ }^{-}$ions (group I, $25 \mu \mathrm{g} \mathrm{mL}{ }^{-1}$ of $\mathrm{Au}$ ) and the AuNPs-loaded nanoemulsion (group VI, $25 \mu \mathrm{g} \mathrm{mL}^{-1}$ of $\mathrm{Au}$ ). The same was for the breast cancer cells treated with pm-rfAPGD-activated water (group II), a water solution of gelatin (group III), and turmeric oil dispersed in water (group IV). No statistically significant effect on the apoptosis rate compared to the control sample was observed and the apoptosis rate of 10-20\% for the different cell lines was established (see Fig. 9). It was previously reported that combo nanoemulsion carrying the Au nanostructures in size $4.7 \pm 1.1 \mathrm{~nm}$ and $3.3 \pm 0.6 \mathrm{~nm}$ successfully induced the apoptosis in the colon cancer cell line [44]. Our study documented that the developed AuNPs-loaded nanoemulsion, carrying AuNPs in similar size $3.2 \pm 0.4 \mathrm{~nm}$, significantly induces the apoptosis of the breast cancer cells compared to the control conditions where the $\mathrm{Au}$ nanostructures are not present, confirming its unique anti-cancer activity.

\section{Scratch Test for the Migration Activity}

Next, the migration activity of the cells treated with all the studied agents was examined. As shown by the other researchers [63], the highest migratory activity is displayed by the MDA-MB-231 cell line, while the non-invasive MCF7 and non-tumor MCF10A cell lines migrate slower. As shown in Fig. 10, only the invasive MDA-MB-231 cell line displayed the impaired cell migration, i.e., the relative scratch closure (RSC) of $18 \%$, when treated
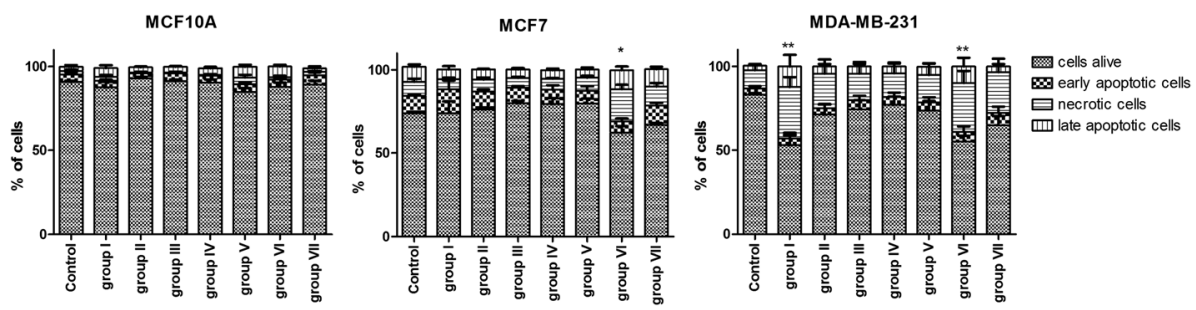

Fig. 9 The percentage of the apoptotic cells. The human breast cell line (MCF10A) and the human cancer cell lines (MCF7 and MDA-MB-231) were treated for $24 \mathrm{~h}$ with different agents (see description of the groups given in Table 2). The percentages of the alive cells, early apoptotic cells, late apoptotic cells and necrotic cells were calculated as the mean \pm SD values of three independent experiments, each performed with triplicate wells for each treatment group. The statistical comparison was performed using the unpaired t-test and compared to the untreated controls $* p<0.05, * * p<0.01$ 

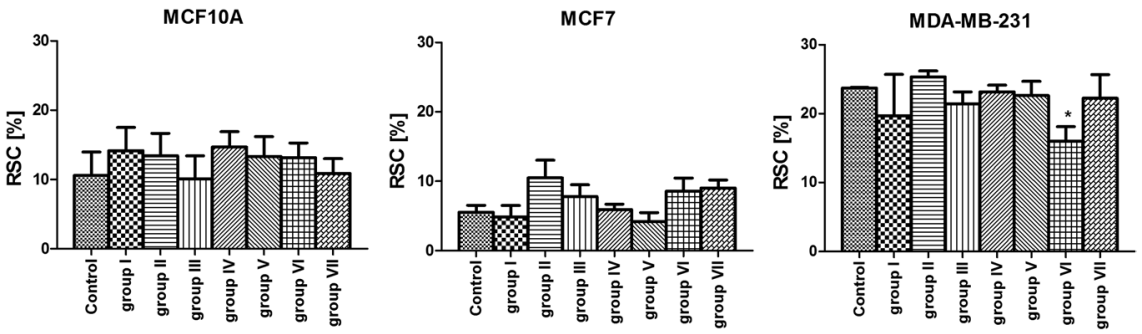

Fig. 10 The scratch assays with the human breast cell line (MCF10A) and the human cancer cell lines (MCF7 and MDA-MB-231) performed to monitor the migratory activity of the cancer cells. All the cell types were grown to confluence and treated with different agents (see description of the group presented in the Table 4) for $24 \mathrm{~h}$. Subsequently, the monolayers were scratched, and the migration rate was measured after $24 \mathrm{~h}$ by quantifying the relative scratch closure (RSC \%). The data are presented as the mean \pm SD values for three analyses done in triplicate. The statistical comparison was performed using the unpaired $t$ test and compared to the untreated controls $* p<0.05$

with the AuNPs-loaded nanoemulsion (group VI, $10 \mu \mathrm{g} \mathrm{mL} \mathrm{m}^{-1}$ of $\mathrm{Au}$ ). Concurrently, the RSC values for the MCF10A and MCF7 cell lines were merely 12 and 8\%. Our results confirmed the previous observations and indicated that the AuNPs-loaded nanoemulsion could successfully be used to inhibit the migration of the invasive cancer cell lines.

\section{Conclusions}

In the current work, the pm-rf-APGD-based high-throughput reaction-discharge system was employed for the synthesis of the size-defined, uncoated AuNPs. Based on the established statistical models, the operating parameters of the system that resulted in the fabrication of the largest raw-AuNPs were selected and their appropriateness was validated in the independent experiments. Loading the pm-rf-APGD-produced size-controlled raw-AuNPs into the nanoemulsion, consisting of turmeric oil and a gelatin aqueous solution, the aggregation and sedimentation of the AuNPs was limited. As compared to the raw-AuNPs, the developed AuNPs-loaded nanoemulsion was found to effectively inhibit the proliferation of the invasive breast cancer cell lines MDA-MB-231 as well as to significantly induce the apoptosis thereof. Hence, the results presented in this work make an important impact on the development of the new anti-breast cancer strategies.

Acknowledgements The presented research was financed by the statutory activity from the Polish Ministry of Science and Higher Education dedicated to the Faculty of Chemistry of Wroclaw University of Science and Technology. A.D. is supported by the Foundation for Polish Science (FNP), program START (UMO-022.2018) and by the Polish Ministry of Science and Higher Education. Authors would like to thank Agnieszka Cwiklinska and Elzbieta Wojdat for the technical support as well as to Prof. George diCenzo for proofreading the manuscript.

Open Access This article is licensed under a Creative Commons Attribution 4.0 International License, which permits use, sharing, adaptation, distribution and reproduction in any medium or format, as long as you give appropriate credit to the original author(s) and the source, provide a link to the Creative Commons licence, and indicate if changes were made. The images or other third party material in this article are included in the article's Creative Commons licence, unless indicated otherwise in a credit line to the material. If material is not included in the article's Creative Commons licence and your intended use is not permitted by statutory regulation or exceeds the permitted use, you will need to obtain permission directly from the copyright holder. To view a copy of this licence, visit http://creativecommons.org/licenses/by/4.0/. 


\section{References}

1. Hanafy N, El-Kemary M, Leporatti S (2018) Micelles structure development as a strategy to improve smart cancer therapy. Cancers 10:238

2. Miyata K, Christie RJ, Kataoka K (2011) Polymeric micelles for nano-scale drug delivery. React Funct Polym 71:227

3. Li C, Zhang J, Zu YJ, Nie SF, Cao J, Wang Q, Nie SP, Deng ZY, Xie MY, Wang S (2015) Biocompatible and biodegradable nanoparticles for enhancement of anti-cancer activities of phytochemicals. Chin J Nat Med 13:641

4. Babu A, Templeton AK, Munshi A, Ramesh R (2014) Nanodrug delivery systems: a promising technology for detection, diagnosis, and treatment of cancer. AAPS PharmSciTech 15:709

5. Lee J, Chatterjee DK, Lee MH, Krishnan S (2014) Gold nanoparticles in breast cancer treatment: promise and potential pitfalls. Cancer Lett 347:46

6. Yezhelyev MV, Gao X, Xing Y, Al-Hajj A, Nie S, O’Regan RM (2006) Emerging use of nanoparticles in diagnosis and treatment of breast cancer. Lancet Oncol 7:657

7. Jain S, Hirst DG, O'Sullivan JM (2012) Gold nanoparticles as novel agents for cancer therapy. Br J Radiol 85:101

8. Jana NR, Gearheart L, Murphy CJ (2001) Evidence for seed-mediated nucleation in the chemical reduction of gold salts to gold nanoparticles. Chem Mater 13:2313

9. Epifani M, Giannini C, Tapfer L, Vasanelli L (2000) Sol-gel synthesis and characterization of Ag and Au nanoparticles in $\mathrm{SiO}_{2}, \mathrm{TiO}_{2}$, and $\mathrm{ZrO}_{2}$ thin films. J Am Ceram Soc 83:2385

10. Dzimitrowicz A, Jamroz P, diCenzo G, Sergiel I, Kozlecki T, Pohl P (2019) Preparation and characterization of gold nanoparticles prepared with aqueous extracts of Lamiaceae plants and the effect of follow-up treatment with atmospheric pressure glow microdischarge. Arab J Chem 12:4118

11. Dreaden EC, Alkilany AM, Huang X, Murphy CJ, El-Sayed MA (2012) The golden age: gold nanoparticles for biomedicine. Chem Soc Rev 41:2740

12. Mariotti D, Patel J, Svrcek V, Maguire P (2012) Plasma-liquid interactions at atmospheric pressure for nanomaterials synthesis and surface engineering. Plasma Process Polym 9:1074

13. Patel J, Nemcova L, Maguire P, Graham WG, Mariotti D (2013) Synthesis of surfactant-free electrostatically stabilized gold nanoparticles by plasma-induced liquid chemistry. Nanotechnology 24:245604

14. Wang R, Zuo S, Wu D, Zhang J, Zhu W, Becker KH, Fang J (2014) Microplasma-assisted synthesis of colloidal gold nanoparticles and their use in the detection of cardiac troponin I (cTn-I). Plasma Process Polym 12:380

15. de Vos C, Baneton J, Witzke M, Dille J, Godet S, Gordon MJ, Sankaran RM, Reniers FA (2017) Comparative study of the reduction of silver and gold salts in water by a cathodic microplasma electrode. J Phys D Appl Phys 50:105206

16. Watzky MA, Finke RG (2018) Gold nanoparticles formation kinetics and mechanism: a critical analysis of the redox crystallization mechanism. ACS Omega 3:1555

17. Huang X, Li Y, Zhong X (2014) Effect of experimental conditions on size control of Au nanoparticles synthesized by atmospheric microplasma electrochemistry. Nanoscale Res Lett 9:572

18. Zhang RC, Sun D, Zhang R, Lin WF, Macias-Montero M, Patel J, Askari S, McDonald C, Mariotti D, Maguire P (2017) Gold nanoparticle-polymer nanocomposites synthesized by room temperature atmospheric pressure plasma and their potential for fuel cell electrocatalytic application. Sci Rep 7:46682

19. Sun D, McLaughlan J, Zhang L, Falzon BG, Mariotti D, Maguire P, Sun D (2019) Atmospheric pressure plasma-synthesized gold nanoparticle/carbon nanotube hybrids for photothermal conversion. Langmuir 35:4577

20. Khatoon N, Ysin HM, Younus M, Ahmed W, Rehman NU, Zakaullah M, Iqbal MZ (2018) Synthesis and spectroscopic characterization of gold nanoparticles via plasma-liquid interaction technique. AIP Adv 8:015130

21. Nolan H, Sun D, Falzon BG, Chakrabarti S, Padmanaba DB, Maguire P, Mariotti D, Yu T, Jones D, Andresws G, Sun D (2018) Metal nanoparticle-hydrogel nanoparticles for biomedical applications: an atmospheric pressure plasma synthesis approach. Plasma Process Polym 15:e1800112

22. Hieda J, Saito N, Takai O (2018) Exotic shapes of gold nanoparticles synthesized using plasma in aqueous solution. J Vac Sci Technol, A 26:854

23. Chen Q, Kaneko T, Hatakeyama R (2011) Effects of DNA on gold nanoparticles synthesis using gasliquid interfacial pulse discharge plasma. Trans Mater Res Soc Jpn 36:483

24. Chen Q, Kaneko T, Hatakeyama R (2012) Rapid synthesis of water-soluble gold nanoparticles with control of size and assembly using gas-liquid interfacial discharge plasma. Chem Phys Lett 521:113 
25. Bouchard M, Laprise-Pelletier M, Turgeon S, Fortin MA (2017) Efficient and rapid synthesis of radioactive gold nanoparticles by dielectric barrier discharge. Part Part Syst Charact 3:1600231

26. Jin Y, Li Z, Hu L, Shi X, Guan W, Du Y (2013) Synthesis of chitosan-stabilized gold nanoparticles by atmospheric plasma. Carbohydr Polym 91:152

27. Kim SM, Kim GS, Lee SY (2008) Effects of PVP and $\mathrm{KCl}$ concentrations on the synthesis of gold nanoparticles using a solution plasma processing. Mater Lett 62:4354

28. Heo YK, Bratescu MA, Ueno T, Saito N (2014) Synthesis of mono-dispersed nanofluids using solution plasma. J Appl Phys 116:024302

29. Shirai N, Uchida S, Tochikubo F (2014) Synthesis of metal nanoparticles by dual plasma electrolysis using atmospheric de glow discharge in contact with liquid. Jpn J Appl Phys 53:046202

30. Tochikubo F, Shimokawa Y, Shirai N, Uchida S (2014) Chemical reactions in liquid induced by atmospheric-pressure de glow discharge in contact with liquid. Jpn J Appl Phys 53:126201

31. Dzimitrowicz A, Lesniewicz T, Greda K, Jamroz P, Nyk M, Pohl P (2015) Production of gold nanoparticles using atmospheric pressure glow discharge generated in contact with a flowing liquid cathode: a design of experiments study. RSC Adv 5:90534

32. Dzimitrowicz A, Jamroz P, Nyk M, Pohl P (2016) Application of direct current atmospheric pressure glow microdischarge generated in contact with a flowing liquid solution for synthesis of AuAg core-shell nanoparticles. Materials 9:268

33. Dzimitrowicz A, Greda K, Lesniewicz T, Jamroz P, Nyk M, Pohl P (2016) Size-controlled synthesis of gold nanoparticles by a novel atmospheric pressure glow discharge system with a metallic pin electrode and a flowing liquid electrode. RSC Adv 6:80773

34. Dzimitrowicz A, Jamroz P, Greda K, Nowak P, Nyk M, Pohl P (2015) The influence of stabilizers on the production of gold nanoparticles by direct current atmospheric pressure glow microdischarge generated in contact with liquid flowing cathode. J Nanopart Res 17:185

35. https://www.wcrf.org/dietandcancer/cancer-trends/breast-cancer-statistics. Accessed 01 August 2019

36. Eroles P, Bosch A, Perez-Fidalgo JA, Lluch J (2012) Molecular biology in breast cancer: intrinsic subtypes and signaling pathways. Cancer Treat Rev 38:698

37. Feng Y, Spezia M, Huang S, Yuan C, Zeng Z, Zhang L et al (2018) Breast cancer development and progression: risk factors, cancer stem cells, signaling pathways, genomics, and molecular pathogenesis. Genes Dis 5:77

38. Davila-Gonzalez D, Choi DS, Rosato RR, Granados-Principal SM, Kuhn JG, Li WF, Qian W, Chen W, Kozielski AJ, Wong H, Dave B, Chang JC (2018) Pharmacological inhibition of NOS activates ASK1/JNK pathway augmenting docetaxel-mediated apoptosis in triple-negative breast cancer. Clin Cancer Res 24:1152

39. Ahmadzada T, Reid G, McKenzie DR (2018) Fundamentals of siRNA and miRNA therapeutics and a review of targeted nanoparticle delivery systems in breast cancer. Biophys Rev 10:69

40. Costa RL, Han HS, Gradishar WJ (2018) Targeting the PI3K/AKT/mTOR pathway in triple-negative breast cancer: a review. Breast Cancer Res Treat 169:397

41. Olov N, Bagheri-Khoulenjani S, Mirzadeh H (2018) Combinational drug delivery using nanocarriers for breast cancer treatments: a review. J Biomed Mater Res B 106:2272

42. Husebo A, Husebo T (2017) Quality of life and breast cancer: how can mind-body exercise therapies help? an overview study. Sports 5:79

43. Sinha R, Kim GJ, Nie S, Shin DM (2006) Nanotechnology in cancer therapeutics: bioconjugated nanoparticles for drug delivery. Mol Cancer Ther 5:1909

44. Huang RFS, Wei YJ, Inbaraj BS, Chen BH (2015) Inhibition of colon cancer cell growth by nanoemulsion carrying gold nanoparticles and lycopene. Int J Nanomed 10:2823

45. Brazzale C, Mastrotto F, Moody P, Watson PD, Balasso A, Malfanti A, Mantovani G, Caliceti P, Alexander C, Jones AT, Salmaso S (2017) Control of targeting ligand display by pH-responsive polymers on gold nanoparticles mediates selective entry into cancer cells. Nanoscale 9:11137

46. Mangadlao JD, Wang X, McCleese C, Escamilla M, Ramamurthy G, Wang Z, Govande M, Basilion JP, Burda C (2018) Prostate-specific membrane antigen targeted gold nanoparticles for theranostics of prostate cancer. ACS Nano 12:3714

47. Zheng Y, Liu W, Chen Y, Jiang H, Wang X (2018) Mercaptopyrimidine-directed gold nanoclusters: a suitable fluorescent probe for intracellular glutathione imaging and selective cancer cell identification. J Mater Chem B 6:3650

48. Leela NK, Tava A, Shafi PM, John SP, Chempakam B (2002) Chemical composition of essential oil of turmeric (Curcuma longa L.). Acta Pharam 52:137

49. Toden S, Theiss AL, Wang X, Goel A (2017) Essential turmeric oils enhance anti-inflammatory efficacy of curcumin in dextran sulfate sodium-induced colitis. Sci Rep 7:814 
50. Zhou S, Zhang S, Shen H, Chen W, Xu H, Chen X, Sun D, Zhong S, Zhao J, Tang J (2017) Curcumin inhibits cancer progression through regulating expression of microRNAs. Tumor Biol 39:1010428317691680

51. Mirzaei H, Masoudifar A, Sahebkar A, Zare N, Sadri Nahand J, Rashidi B, Mehrabian E, Mohammadi M, Mirzaei HR, Jaafari MR (2018) MicroRNA: a novel target of curcumin in cancer therapy. J Cell Physiol 233:3004

52. Dan P, Karp JM, Hong S, Farokhzad OC, Margalit R, Langer R (2007) Nanocarriers as an emerging platform for cancer therapy. Nat Nanotechnol 12:751

53. Mura S, Nicolas J, Couvreur P (2003) Stimuli-responsive nanocarriers for drug delivery. Nat Mater 12:991

54. Dzimitrowicz A, Bielawska-Pohl A, diCenzo G, Jamroz P, Macioszczyk J, Klimczak A, Pohl P (2018) Pulse-modulated radio-frequency alternating-current-driven atmospheric-pressure glow discharge for continuous-flow synthesis of silver nanoparticles and evaluation of their cytotoxicity toward human melanoma cells. Nanomaterials 8:398

55. Sun Y, Xia Y (2002) Shape-controlled synthesis of gold and silver nanoparticles. Science 298:2176

56. Goswami AM, Ghosh S (2013) Biological synthesis of colloidal gold nanoprisms using Penicillium citrinum MTCC9999. J Biomater Nanobiotechnol 4:20

57. Bandekar J (1992) Amide modes and protein conformation. Biochim Biophys Acta 1120:123

58. Hoque MS, Benjakul S, Prodpran T (2010) Effect of heat treatment of film-forming solution on the properties of film from cuttlefish (Sepia pharaonis) skin gelatin. J Food Eng 96:66

59. Brychcy E, Malik M, Drozdzewski P, Krol Z, Jarmoluk A (2015) Physicochemical and antibacterial properties of carrageenan and gelatine hydrosols and hydrogels incorporated with acidic electrolyzed water. Polymers 7:2638

60. Krol Z, Malik M, Marycz K, Jarmoluk A (2016) Characteristic of gelatine, carrageenan and sodium alginate hydrosols treated by direct electric current. Polymers 8:1

61. Araujo L et al (2016) Physicochemical/photophysical characterization and angiogenic properties of Curcuma longa essential oil. An Acad Bras Cienc 88:1889

62. Surapaneni SK, Bashir S, Tikoo K (2018) Gold nanoparticles-induced cytotoxicity in triple negative breast cancer involves different epigenetic alterations depending upon the surface charge. Sci Rep $8: 12295$

63. Razak NA et al (2019) Cytotoxicity of eupatorin in MCF-7 and MDA-MB-231 human breast cancer cells via cell cycle arrest, anti-angiogenesis and induction of apoptosis. Sci Rep 9:1514

Publisher's Note Springer Nature remains neutral with regard to jurisdictional claims in published maps and institutional affiliations.

\section{Affiliations}

\section{Anna Dzimitrowicz ${ }^{1} \cdot$ Aleksandra Bielawska-Pohl $^{2} \cdot$ Pawel Pohl $^{1}$. Dorota Jermakowicz-Bartkowiak ${ }^{3}$ - Piotr Jamroz ${ }^{1} \cdot$ Magdalena Malik-Gajewska $^{4}$. Aleksandra Klimczak ${ }^{2} \cdot$ Piotr Cyganowski $^{3}$}

1 Department of Analytical Chemistry and Chemical Metallurgy, Faculty of Chemistry, Wroclaw University of Science and Technology, Wybrzeze St. Wyspianskiego 27, 50-370 Wroclaw, Poland

2 Laboratory of Biology of Stem and Neoplastic Cells, Hirszfeld Institute of Immunology and Experimental Therapy Polish Academy of Science, R. Weigla 12, 53-114 Wroclaw, Poland

3 Department of Polymer and Carbonaceous Materials, Faculty of Chemistry, Wroclaw University of Science and Technology, Wybrzeze St. Wyspianskiego 27, 50-370 Wroclaw, Poland

4 Department of Inorganic and Structural Chemistry, Faculty of Chemistry, Wroclaw University of Science and Technology, Wybrzeze St. Wyspianskiego 27, 50-370 Wroclaw, Poland 